\title{
WestVirginiaUniversity
}

THE RESEARCH REPOSITORY @ WVU

Graduate Theses, Dissertations, and Problem Reports

2014

\section{A Lumped Computational Model for Sodium Sulfur Battery Analysis}

Fan Wu

West Virginia University

Follow this and additional works at: https://researchrepository.wvu.edu/etd

\section{Recommended Citation}

Wu, Fan, "A Lumped Computational Model for Sodium Sulfur Battery Analysis" (2014). Graduate Theses, Dissertations, and Problem Reports. 672.

https://researchrepository.wvu.edu/etd/672

This Thesis is protected by copyright and/or related rights. It has been brought to you by the The Research Repository @ WVU with permission from the rights-holder(s). You are free to use this Thesis in any way that is permitted by the copyright and related rights legislation that applies to your use. For other uses you must obtain permission from the rights-holder(s) directly, unless additional rights are indicated by a Creative Commons license in the record and/ or on the work itself. This Thesis has been accepted for inclusion in WVU Graduate Theses, Dissertations, and Problem Reports collection by an authorized administrator of The Research Repository @ WVU. For more information, please contact researchrepository@mail.wvu.edu. 


\title{
A Lumped Computational Model for Sodium Sulfur Battery Analysis
}

\author{
Fan Wu
}

Thesis submitted to the

Benjamin M. Statler College of Engineering \& Mineral Resources at West Virginia University in partial fulfillment of the requirements for the degree of Master of Science in Mechanical Engineering

\author{
Ismail B. Celik, Ph.D., Chair \\ V'yacheslav Akkerman, Ph.D. \\ Xingbo Liu, Ph.D. \\ Terence Musho, Ph.D.
}

Department of Mechanical and Aerospace Engineering

Morgantown, West Virginia 2014

Keywords: NaS Battery, Lumped Model, Numerical Modeling Copyright 2014 Fan Wu 


\begin{abstract}
A Lumped Computational Model for Sodium Sulfur Battery Analysis
\end{abstract}

\title{
Fan Wu
}

Due to the cost of materials and time consuming testing procedures, development of new batteries is a slow and expensive practice. The purpose of this study is to develop a computational model and assess the capabilities of such a model designed to aid in the design process and control of sodium sulfur batteries.

To this end, a transient lumped computational model derived from an integral analysis of the transport of species, energy and charge throughout the battery has been developed. The computation processes are coupled with the use of Faraday's law, and solutions for the species concentrations, electrical potential and current are produced in a time marching fashion. Properties required for solving the governing equations are calculated and updated as a function of time based on the composition of each control volume.

The proposed model is validated against multi- dimensional simulations and experimental results from literatures, and simulation results using the proposed model is presented and analyzed. The computational model and electrochemical model used to solve the equations for the lumped model are compared with similar ones found in the literature. The results obtained from the current model compare favorably with those from experiments and other models. 


\section{Acknowledgement}

My deepest gratitude goes first to my advisor, Dr. Celik, for his mentoring, constant encouragement, guidance and financial support in my graduate studies. Without his illuminating instruction, this thesis could not have reached its present form. I am grateful to my other committee members Dr. Akkerman, Dr. Musho and Dr. Liu for taking the precious time to review my work and giving me help and great support. I would also appreciate Center for Electrochemical Energy Storage (CEES) that made my current research work possible. And I would like to thank Dr. Sun for all the support and great help.

I also owe my sincere gratitude to my friends in our Computational Fluid Dynamics and Applied Multi-Physics (CFD\&AMP) Center, especially Tao Yang, Steven Rowan, Jerry Mason, Hayri Sezer, Engin Baran and Sergio Escobar for all the help and good time. I would also like to acknowledge the help from Yi Liu, Kuijun Li and all my other friends. Above all, I would like to thank my parents for their love and everlasting support. 


\section{Table of Contents}

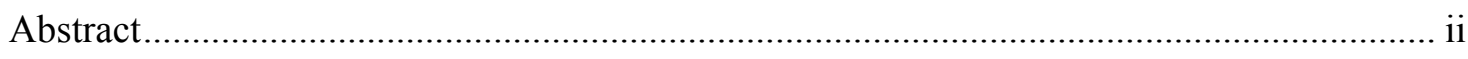

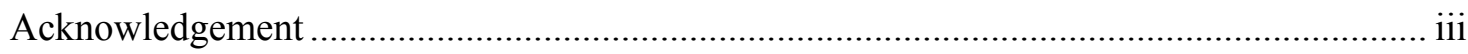

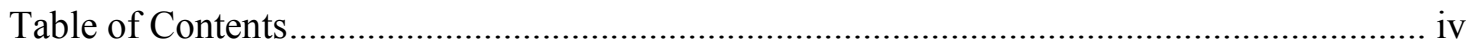

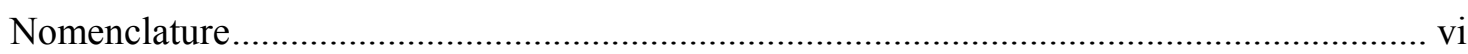

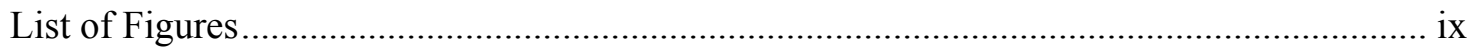

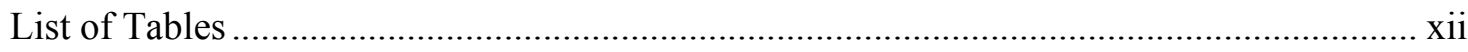

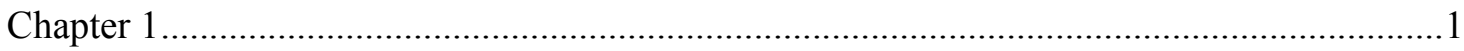

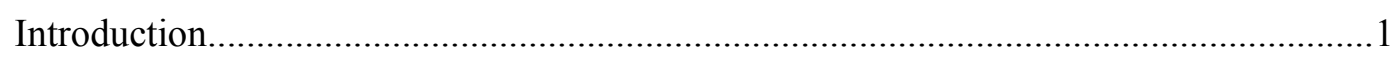

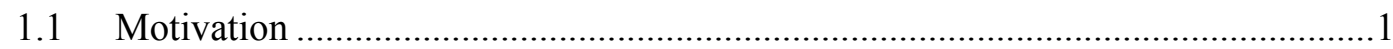

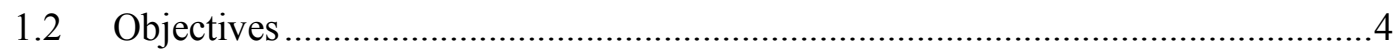

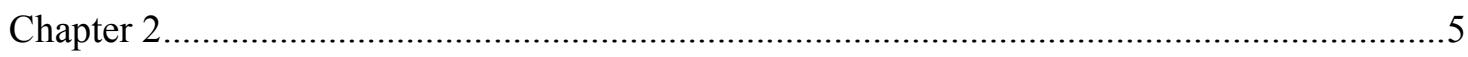

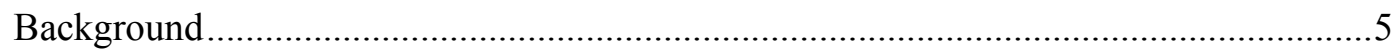

2.1 Development of Sodium Sulfur Batteries.........................................................

2.2 Operating Principle of Sodium Sulfur Batteries ................................................

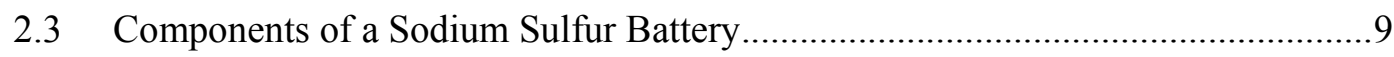

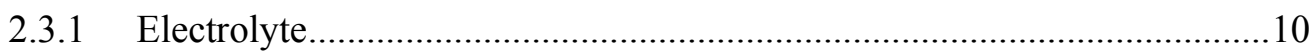

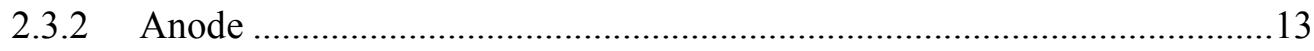

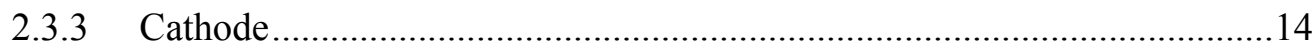

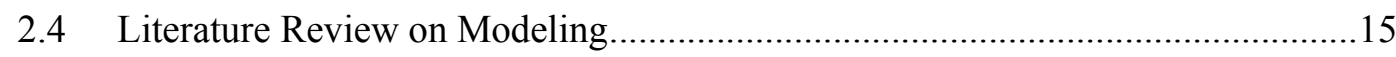

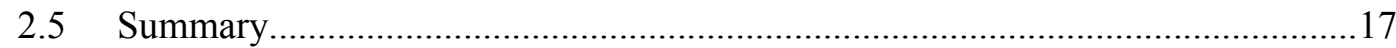

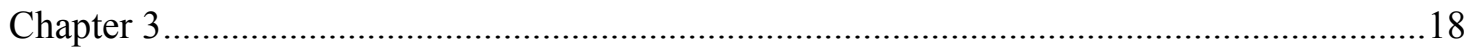

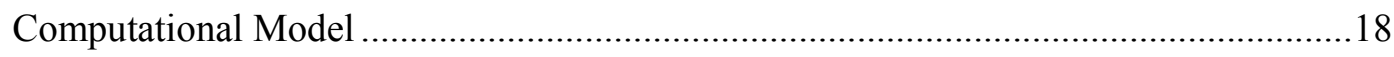

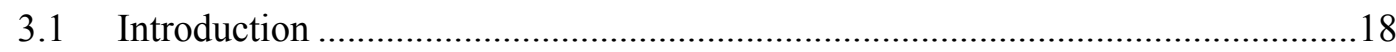

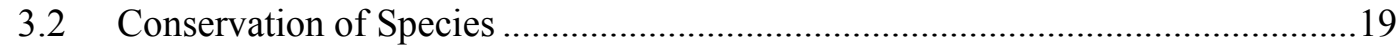

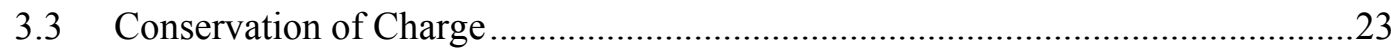




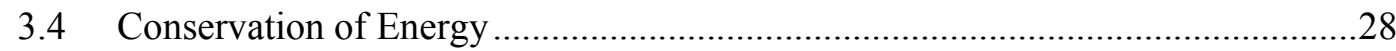

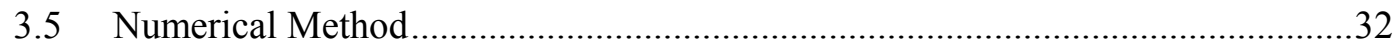

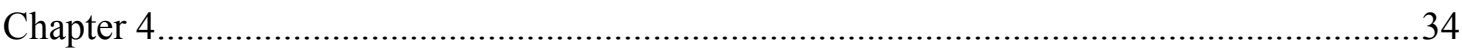

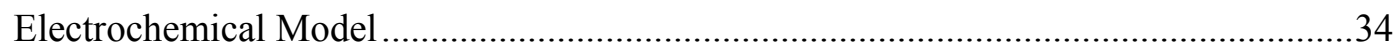

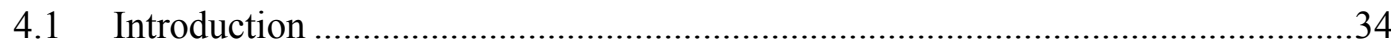

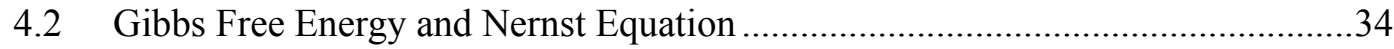

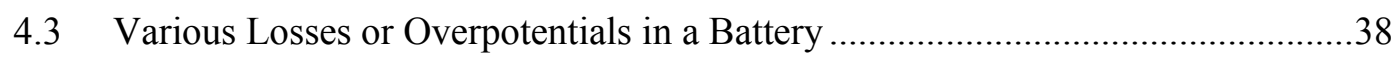

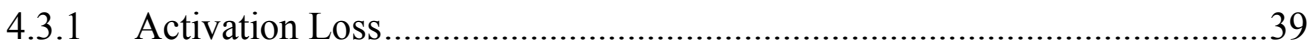

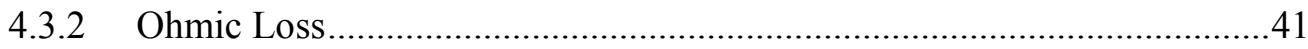

4.3.3 Mass Transport/Concentration Loss ......................................................42

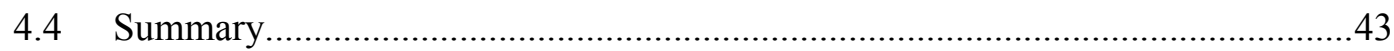

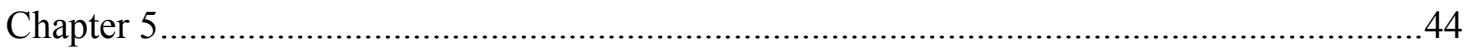

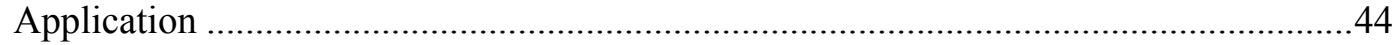

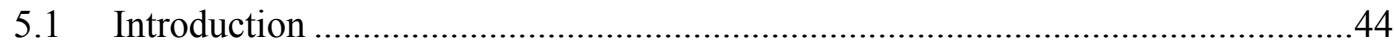

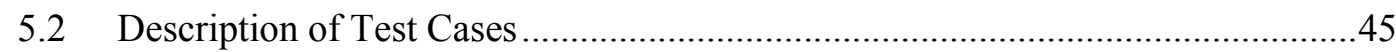

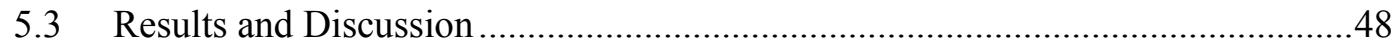

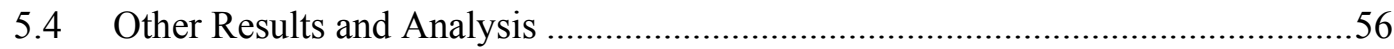

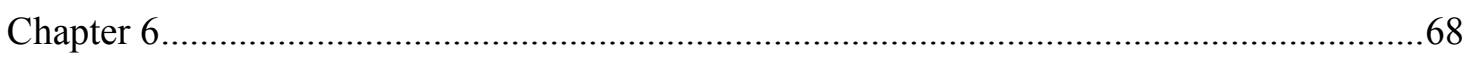

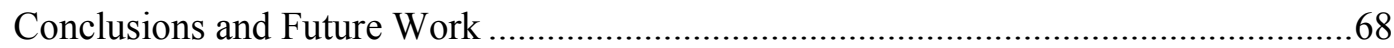

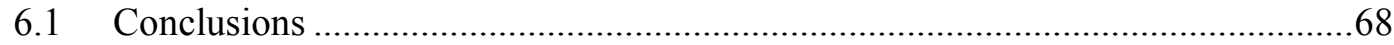

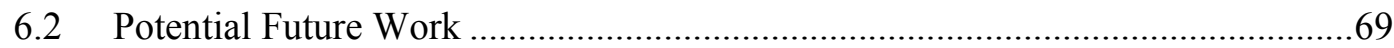

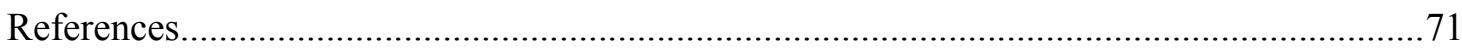

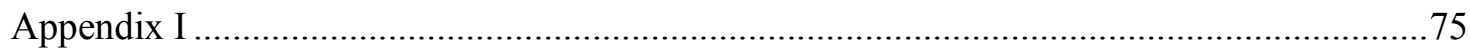

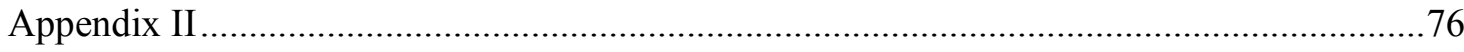




\section{Nomenclature}

\begin{tabular}{|c|c|}
\hline$A$ & area \\
\hline$A_{\text {eff }}$ & effective area \\
\hline$a$ & chemical activity \\
\hline$a_{\text {int }}$ & interface area density \\
\hline$b$ & molality \\
\hline$b^{\theta}$ & standard molality \\
\hline$C_{\mathrm{DL}}$ & double layer capacitance \\
\hline$c$ & molar concentration \\
\hline$c^{\theta}$ & standard molar concentration \\
\hline$c_{p}$ & specific heat capacitance \\
\hline$E$ & voltage \\
\hline$E^{o}$ & standard electromotive force \\
\hline$e$ & electron \\
\hline$F$ & the Faraday constant \\
\hline $\bar{g}$ & Gibbs Free energy per mole \\
\hline $\bar{h}$ & molar enthalpy \\
\hline$I$ & current \\
\hline$I_{F}$ & faradaic current \\
\hline$i_{o}$ & exchange current density \\
\hline$i_{o}^{*}$ & reference current density \\
\hline$J$ & current density \\
\hline$k$ & thermal conductivity \\
\hline$l_{e f f}$ & effective length \\
\hline$M$ & molar mass \\
\hline$m$ & mass \\
\hline$\dot{m}$ & mass flow rate \\
\hline$N$ & Avogadro's number \\
\hline
\end{tabular}




$\begin{array}{ll}n & \text { number of moles } \\ Q & \text { heat } \\ q & \text { charge } \\ R & \text { universal gas constant } \\ R_{O} & \text { electrical resistance of the battery } \\ \bar{S} & \text { molar entropy } \\ T & \text { temperature } \\ t & \text { time } \\ V & \text { volume } \\ z & \text { valency number }\end{array}$

Greeks

$\begin{array}{ll}\alpha & \text { transfer coefficient } \\ \beta & \text { tortuosity factor } \\ \varepsilon & \text { porosity or volume fraction } \\ \phi & \text { potential } \\ \gamma_{b} & \text { activity coefficient for molality } \\ \gamma_{c} & \text { activity coefficient for concentration } \\ \eta & \text { overpotential } \\ \eta_{a c t} & \text { activation potential } \\ \rho & \text { density } \\ \sigma & \text { electric conductivity }\end{array}$

Subscripts

$\begin{array}{ll}A & \text { anode } \\ C & \text { cathode } \\ E & \text { electrolyte } \\ e & \text { electron } \\ i & \text { ion }\end{array}$




$\begin{array}{ll}j & \text { neighboring point } \\ p & \text { center point } \\ s & \text { species }\end{array}$

\section{Superscripts}

$\begin{array}{ll}e & \text { electron } \\ i & \text { ion } \\ n & \text { time level } \\ \text { prod } & \text { production } \\ \text { used } & \text { consumption }\end{array}$




\section{List of Figures}

Figure 2.1 Operating principle of NaS battery for discharging 8

Figure 2.2 Schematic plot of tubular NaS battery 9

$\begin{array}{ll}\text { Figure 2.3 Structure of beta-alumina } & 11\end{array}$

$\begin{array}{lr}\text { Figure 2.4 Structure of NaSICON } & 12\end{array}$

Figure 3.1 Control volumes used for lumped model of NaS battery 18

Figure 5.1 schematic drawing of the NaS battery 46

Figure 5.2 Voltage results at 130/130 mA/ $\mathrm{cm}^{2}$ charge/discharge from lumped model

Figure 5.3 Temperature results at 130/130 mA/ $\mathrm{cm}^{2}$ charge/discharge from lumped model

Figure 5.4 Results at 130/130 mA/ $\mathrm{cm}^{2}$ charge/discharge from [1]

Figure 5.5 Voltage results at 195/260 mA/ $\mathrm{cm}^{2}$ charge/discharge from lumped model

Figure 5.6 Temperature results at 195/260 mA/ $\mathrm{cm}^{2}$ charge/discharge from lumped model

Figure 5.7 Results at 195/260 mA/ $\mathrm{cm}^{2}$ charge/discharge from [1]

Figure 5.8 Voltage results at $260 / 390 \mathrm{~mA} / \mathrm{cm}^{2}$ charge/discharge from lumped model

Figure 5.9 Temperature results at 260/390 mA/ $\mathrm{cm}^{2}$ charge/discharge from lumped model 
Figure 5.10 Results at 260/390 mA/ $\mathrm{cm}^{2}$ charge/discharge from [1]

Figure 5.11 Voltage simulation running in cycles from lumped model

Figure 5.12 Temperature simulation running in cycles from lumped model

Figure 5.13 Electric characteristics of the NaS battery at $130 / 130 \mathrm{~mA} / \mathrm{cm}^{2}$

Figure 5.14 Cell resistance of the NaS battery at $130 / 130 \mathrm{~mA} / \mathrm{cm}^{2}$

Figure 5.15 Electric characteristics of the NaS battery at 195/260 mA/cm²

Figure 5.16 Cell resistance of the NaS battery at 195/260 mA/cm²

Figure 5.17 Electric characteristics of the NaS battery at $260 / 390 \mathrm{~mA} / \mathrm{cm}^{2}$

Figure 5.18 Cell resistance of the NaS battery at $260 / 390 \mathrm{~mA} / \mathrm{cm}^{2}$

Figure 5.19 Thermal characteristics of the NaS battery at $130 / 130 \mathrm{~mA} / \mathrm{cm}^{2}$

Figure 5.20 Temperature profiles at the beginning of discharging

Figure 5.21 Temperature for anode and electrolyte (a)

Figure 5.22 Temperature for anode and electrolyte (b)

Figure 5.23 Voltage results at $\mathrm{dt}=0.1 \mathrm{~s}$

Figure 5.24 Voltage results at $\mathrm{dt}=1 \mathrm{~s}$

Figure 5.25 Temperature results at $\mathrm{dt}=0.1 \mathrm{~s}$

Figure 5.26 Temperature results at $\mathrm{dt}=1 \mathrm{~s}$ 
Figure 5.30 Temperature results under given periodic current density

Figure 5.31 (a) Voltage results for discharging

Figure 5.31 (b) Voltage results for charging 


\section{List of Tables}

Table 2.1 Comparison of performances between five types of batteries

Table 5.1 Dimensions of the NaS battery

Table 5.2 Key properties at 300 to $400^{\circ} \mathrm{C}$ used in the $\mathrm{NaS}$ battery 48 


\section{Chapter 1}

\section{Introduction}

\subsection{Motivation}

Due to the development of a high-technology society, it is hard to imagine a world without sufficient power supply. The dependence of the energy resources on conventional fossil fuels cannot be sustainable due to the limitation of coal, gas, petroleum, and the huge greenhouse gases may emit when utilized for power generation. Therefore, alternative energy technologies such as wind, solar and hydropower are being developed increasingly in recent decades to overcome the energy crises. However, because of the intermittent nature of solar and wind power, it is necessary to develop efficient energy devices to store the energy when there is high production, and use it when there is high demand.

A major problem under such a background lies in the electric voltage and frequency fluctuation on the power network brought about by the unpredictable supply of renewable energy. These fluctuations are detrimental to electric power grid and can cause serious problems. Even for the conventional ways of energy supply, the massive difference of the electric demand between day and night, as well as throughout the seasons, is also a big problem that cannot be avoided. It has been difficult to construct power stations and transmission facilities which cover peak power demands not only from the point of construction cost but also conservation of resources. Therefore, reliable power storage systems are in desperate need to smooth out the fluctuation in demand and supply of energy.

Grid energy storage applications use rechargeable batteries for renewable energy uses, such as storing power generated from photovoltaic arrays during the day to be used at night, and for load leveling, where they store electric energy for use during peak load 
periods. By charging batteries during periods of low demand and returning energy to the grid during periods of high electrical demand, load-leveling helps eliminate the need for expensive peaking power plants and helps amortize the cost of generators over more hours of operation.

A rechargeable battery, or sometimes called storage battery or accumulator, is essentially a type of electrical battery. It comprises one or more electrochemical cells, and is a type of energy accumulator used for electrochemical energy storage. It is technically known as a secondary battery because its electrochemical reactions are electrically reversible, while ordinary batteries, the opposite type, are intended for single use applications as they release energy through an irreversible chemical reaction. Rechargeable batteries come in many different shapes and sizes, ranging from button cells to megawatt systems, connected to stabilize an electrical distribution network.

Apart from the potential to reduce the variability of electric power demand from peak shaving and valley filling and means for addressing the intermittencies associated with renewable energy generated from photovoltaic and wind power plants, rechargeable batteries are also central to the portable consumer electronics market. They power critical biomedical devices such as cardiac pacemakers, improve the fuel economy performance and emissions characteristics of hybrid electric vehicles by enabling regenerative braking, optimal power management, etc. [2]

Several different combinations of chemicals are commonly used in rechargeable batteries, including: lead-acid, nickel cadmium ( $\mathrm{NiCd})$, nickel metal hydride $(\mathrm{NiMH})$, lithium ion (Li-ion), lithium ion polymer (Li-ion polymer) and sodium-sulfur $(\mathrm{NaS})$ batteries. Rechargeable batteries have a higher initial cost but can be recharged inexpensively and reused many times, thus providing a lower total cost of use with environmental impact than disposable batteries. 
$\mathrm{NaS}$ batteries are one of the emerging technologies in the field of rechargeable battery market that have advantages in their high energy density and high efficiency. They are well suited for a power storage system. It would be ideal to maximize a $\mathrm{NaS}$ battery's power and energy through cycles of deep charge and discharge at a high current over a broad temperature range for a power storage system. However, this ideal temperature-blind, deep and aggressive battery utilization is difficult to achieve for at least three reasons: First, aggressive battery use may be far from efficient. Higher currents may result in larger dissipative losses which harms efficiency. Second, it may hinder the anode or cathode substances from having sufficient time to spread evenly throughout the electrolyte when charging or discharging a NaS battery at high currents. This action may diminish useful capacity of a NaS battery. Third, aggressive use of a $\mathrm{NaS}$ battery could also reduce the battery life, as it accelerates aging and degradation.

Therefore, theoretical and experimental analysis and management of $\mathrm{NaS}$ battery operation and performance is necessary for design analysis, conceptual system requirements and operation. However, due to the cost of materials and time consuming testing procedures, development of new battery and technology is a slow and expensive practice; the NaS battery control is even a bigger issue. The purpose of this study is to develop a computational model and assess the capabilities of such a model designed to aid in the technical design process and control of $\mathrm{NaS}$ batteries.

This is often a very difficult task when all intricacies of the fundamental phenomena are considered including three-dimensionality and transients. A viable alternative is to use lumped models where integral parameters are used.

The motivation of this work is the necessity of a computational tool that can support the design and development of $\mathrm{NaS}$ batteries. The present model is a lumped model developed for NaS batteries, but could be adapted to study the behavior of other battery systems under given operating conditions with the use of small scale experimental 
results for model validation. The proposed model is validated against multi- dimensional simulations and experimental results from literatures.

\subsection{Objectives}

The main focus of the present work is to develop a zero-dimensional, transient, lumped model to simulate and assess the performance of $\mathrm{NaS}$ batteries. The model is derived from integral analysis of the transport of mass, energy and charge throughout the battery. The processes are coupled with the use of Faraday's law of electrolysis, and solutions for the species concentrations, electrical potential and current density are produced in a time marching fashion.

The present work aims to decrease the time and expense required to complete the design procedure of $\mathrm{NaS}$ batteries. Physical processes, including energy, specie and charge transfer, are simulated numerically by integrating their respective governing equations. Properties required for solving the transport equations, such as fluid density and ionic/electric conductivity are calculated and updated as a function of time. Electrochemical boundary conditions can be as simple as a prescribed voltage or current density, or more practical such as applying resistance, power consuming, power producing loads, etc.

In the following chapters a brief introduction to the technology of $\mathrm{NaS}$ battery and its modeling are presented. The computational model and electrochemical model used to solve the equations for zero-dimensional $\mathrm{NaS}$ battery model are established in Chapters 3 and 4 respectively. The verification and validation, as well as application of the lumped model to a NaS battery with beta-alumina as the solid electrolyte are presented in Chapter 5. In Chapter 6, conclusions of the present work are made and possible future work is described. 


\section{Chapter 2}

\section{Background}

\subsection{Development of Sodium Sulfur Batteries}

$\mathrm{NaS}$ battery has become one of the most promising technologies for energy storage application developed during recent decades. Details of the NaS battery were first released in 1966 by Ford Motor Company to power early-model electric cars [3]. However, it is revealed that the advantage of using NaS battery on electric cars is far from prominent, and safety was a great problem in those early times.

The major development of NaS battery utilization began from an intensive research as part of the "Moonlight Project" of Japan in 1980. This project sought to develop a durable utility power storage device that meets the criteria of $1,000 \mathrm{~kW}$ class, 8 hour charge/ 8 hour discharge at rated load, efficiency of $70 \%$ or better and lifetime of 1,500 cycles or better. The other three types of batteries were: improved lead-acid $(\mathrm{PbA})$, redox flow (vanadium type, $\mathrm{VRB})$, and zinc-bromide $(\mathrm{ZnBr})$ batteries.

To remain commercially viable, batteries must compete with rival technologies on multiple metrics. Table 2.1 shows some comparison between these four types of batteries as well as Li-ion, another common type of battery [4] [5]. 
Table 2.1 Comparison of performances between five types of batteries [4] [5]

\begin{tabular}{|c|c|c|c|c|c|}
\hline Item & $\mathrm{NaS}$ & $\mathrm{PbA}$ & $\mathrm{VRB}$ & $\mathrm{ZnBr}$ & $\mathrm{Li}-$ ion \\
\hline Energy efficiency & $0.75-0.83$ & $0.70-0.84$ & $0.60-0.80$ & $0.60-0.73$ & $0.85-0.95$ \\
\hline Cycling time (80\%DOD) & $4500-5000$ & $400-1000$ & $3000-4000$ & $2500-3000$ & $5000-7000$ \\
\hline Storage life (yr) & $14-16$ & $8-12$ & $15-20$ & $8-10$ & $14-16$ \\
\hline $\begin{array}{c}\text { Raw material cost } \\
(\mathrm{MJ} / \mathrm{Wh})\end{array}$ & 0.29 & 0.45 & 1.4 & 0.3 & 0.31 \\
\hline Production cost $(\mathrm{MJ} / \mathrm{Wh})$ & 0.6 & 0.42 & 0.94 & 0.6 & 1.2 \\
\hline
\end{tabular}

Among these new battery types, NaS batteries are a new practical and economical competitive solution to store large amounts of energy. They exhibit many advantages such as high power and energy density, the use of non-polluting components and longer life [6].

The joint collaboration of NGK Insulator, Ltd. (NGK, a Japanese ceramics company) and Tokyo Electric Power Company (TEPCO) in Japan have refined it for the power grid since 1984. NGK commenced commercial-scale production in April 2003. After initial introduction to the Japanese market, project development and deployment activities are in progress in North America and Europe. Together with the development of the $\mathrm{NaS}$ battery, an $\mathrm{AC} / \mathrm{DC}$ power conversion system from power electronics has also been developed using a large capacity power transistor (IGBT), which leads to a verified high efficiency and compact design of a NaS battery system [7]. NaS batteries have been applied in various ways such as load leveling, combined emergency power supply, electric transmission, distribution system support and uninterruptible power supply [8]. The markets involve industrial, commercial owners and wind power generating systems. Using power electronics, these new batteries can be used for peak saving or power quality purposes on power grid [9]. 


\subsection{Operating Principle of Sodium Sulfur Batteries}

$\mathrm{NaS}$ cell is a rechargeable oxidation-and-reduction battery based on the electrochemistry between molten sulfur and molten sodium. Sodium and sulfur are applied as the anode and cathode respectively, and a kind of solid ceramics is used as both the electrolyte and a separator simultaneously. The fundamental electrochemical phenomenon which allows for the idea of a NaS battery to be plausible is defined as follows:

$$
2 \mathrm{Na}+x \mathrm{~S} \rightleftharpoons \mathrm{Na} \mathrm{S}_{x}
$$

where the forward reaction is for discharging and the backward reaction is for charging, and $x$ is between 2 to 5 , depending on its actual process of charge/discharge.

In the discharging mode, the basic reactions are

Oxidation at anode

$$
2 \mathrm{Na} \rightarrow 2 \mathrm{Na}^{+}+2 e^{-}
$$

Reduction at cathode

$$
2 N a^{+}+x S+2 e^{-} \rightarrow N a_{2} \mathrm{~S}_{x}
$$

or

$$
x S+2 e^{-} \rightarrow S_{x}^{2-}
$$

Overall reaction

$$
2 \mathrm{Na}+x \mathrm{~S} \rightarrow \mathrm{Na}_{2} \mathrm{~S}_{x}
$$


During battery discharging, sodium is ionized within a sodium based electrode (anode). These ions are then allowed to pass through an electrolyte into a sulfur based electrode (cathode). Meanwhile the electrons given off by the sodium are passed via an electrical load, such as resistor, wire, etc., to the cathode in the form of an electrical current. At this point the above reactions can be completed, and energy is released to the load at external circuit. The battery discharging process is depicted in Figure 2.1, where $\mathrm{Na}, \mathrm{Na}^{+}, \mathrm{S}, \mathrm{Na}_{2} \mathrm{~S}_{x}$ and $e^{-}$refer to sodium, sodium ion, sulfur, sodium polysulfide and electron, respectively.

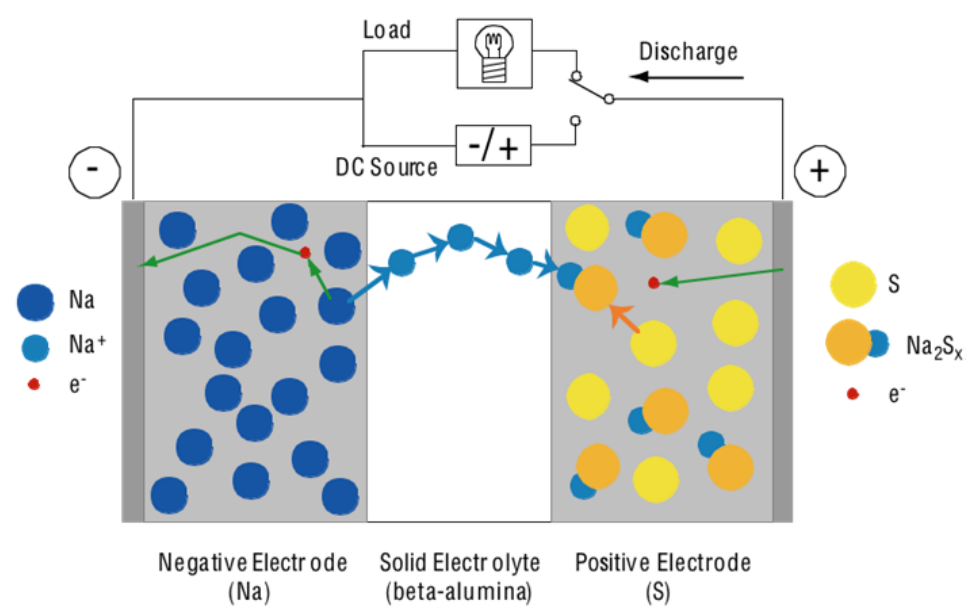

Figure 2.1 Operating principle of NaS battery for discharging [8]

The whole process can be reversed in order to charge the battery. In this process, external current pulls electrons from the positive electrode and injects them into the negative electrode. External work is done on the battery, since current is forced uphill against an electric potential. Inside the battery, energy is stored through the transfer of ions to the negative electrode.

The special thing about the NaS battery is that the reactions which involve the formation and decomposition of various polysulfides determines the way $\mathrm{NaS}$ battery charges and discharges [10]. If the battery is over charged, there would be a large 
resistance in the cathode. In this case, a current being compelled to pass through the battery would damage the battery. On the other hand, if the battery is over discharged, lack of sodium in the anode would lead to degradation of the solid electrolyte. Thus, the act of over charge and over discharge should be avoided during the operation of $\mathrm{NaS}$ batteries.

\subsection{Components of a Sodium Sulfur Battery}

The fundamental components of a NaS battery are as simple as sodium/sodiumion and sulfur/polysulfide separated by a solid electrolyte.

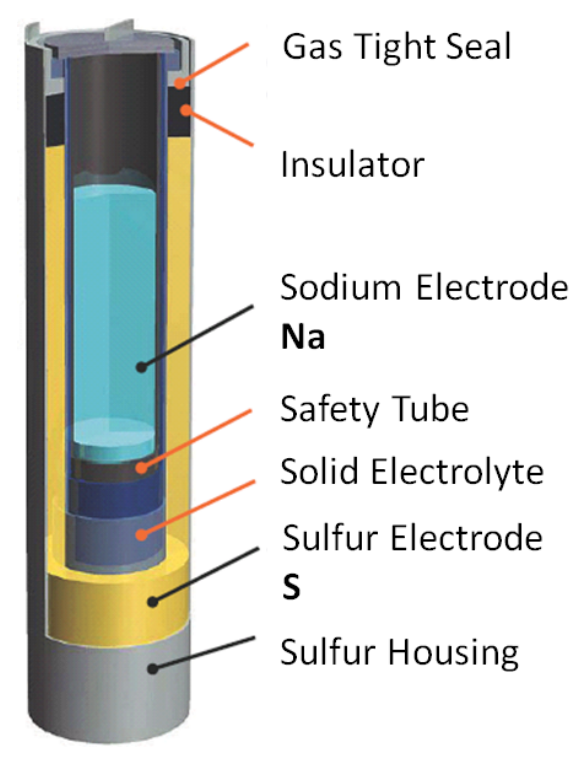

Figure 2.2 Schematic plot of tubular NaS battery [8]

One of the popular types of a NaS battery is a tubular cell, which includes a cylindrical outer housing, serving as a positive terminal, and a cylindrical shell of solid ceramic electrolyte within the outer housing. Sodium is placed in the inner chamber 
formed within the solid electrolyte, and sulfur is placed in the outer chamber formed between the electrolyte and the outer housing [11], as shown in Figure 2.2.

Another common type of NaS battery is a planar cell. The geometry of this kind of cell is larger in lateral extent relative to its height compared to the tubular cell, and that the anode and cathode are generally planar. The advantage of the planar cell is that the active area of electrolyte is relatively larger per unit weight of cell than for a tubular design [12]. However, strength and fabrication issues impose some limitations on this type of design.

\subsubsection{Electrolyte}

Solid electrolytes are one of the functional materials applied in industries because of their high ion conducting property. It provides scientific support for a wide variety of advanced electrochemical devices such as fuel cells, batteries, gas separation membranes, chemical sensors and in the last few years, ionic switches [13] [14].

As discussed in the previous sections, a solid electrolyte membrane is required for $\mathrm{NaS}$ battery that selectively allows sodium-ion to transport between a positive and negative electrode. As the solid electrolyte and electrical separator for NaS battery, the material of the electrolyte requires some essential characteristics:

- High ionic conductivity

- High electrical resistivity

- High mechanical strength and dimensional stability. 
- High density without porosity.

- Long-term durability for a stable battery operation

The most widely used solid electrolyte in the past decades has been beta-alumina $\left(11 \mathrm{Al}_{2} \mathrm{O}_{3}-x \mathrm{Na}_{2} \mathrm{O}\right.$, with $x$ between 1.0 - 1.6) [15]. Effective working temperature for this kind of battery is about $300-350^{\circ} \mathrm{C}$ [16]. The structure of beta-alumina is depicted in Figure 2.3.

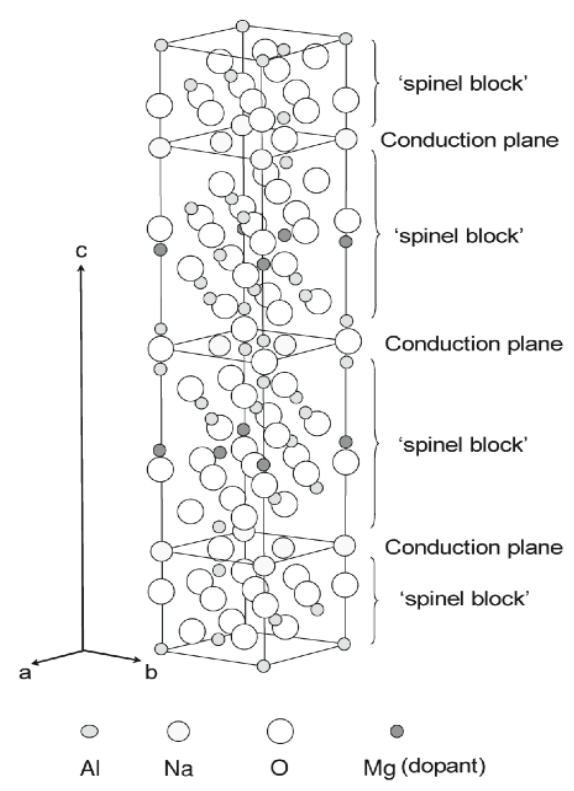

Figure 2.3 Structure of beta-alumina [8]

The beta-alumina tubes provide two primary functions: (1) a low resistance path for sodium-ion transfer between electrodes, and (2) electrical isolation of the positive and negative electrodes. For $\mathrm{NaS}$ batteries to be commercially viable, $\beta$-alumina tubes have been successfully performing these functions with high efficiency, high reliability, and low cost. The development of large beta-alumina tubes with both low sodium-ionic resistivity and high mechanical strength has contributed greatly to establishing the $\mathrm{NaS}$ battery as a superior energy storage medium. 
A lower temperature version of the $\mathrm{NaS}$ battery is being developed in recent years. They use a new NaSICON (sodium super-ionic conductor) membrane to allow operation at around $100^{\circ} \mathrm{C}$ with all components remaining solid [17]. The general form of NaSICON is expressed as $\mathrm{Na}_{1+x} \mathrm{Zr}_{2} \mathrm{P}_{3-x} \mathrm{Si}_{x} \mathrm{O}_{12}$, and its structure is depicted in Figure 2.5 .

NaSICON type ion conductors have been tested widely in energy applications for instance in electric vehicles. High ion conductivity, due to $\mathrm{ZrO}_{2}$ phases (the brown octahedrons in Figure 2.4), and stability of phosphate units (the blue tetrahedrons in Figure 2.4) are advantages of NaSICON over other electrolyte materials [18].

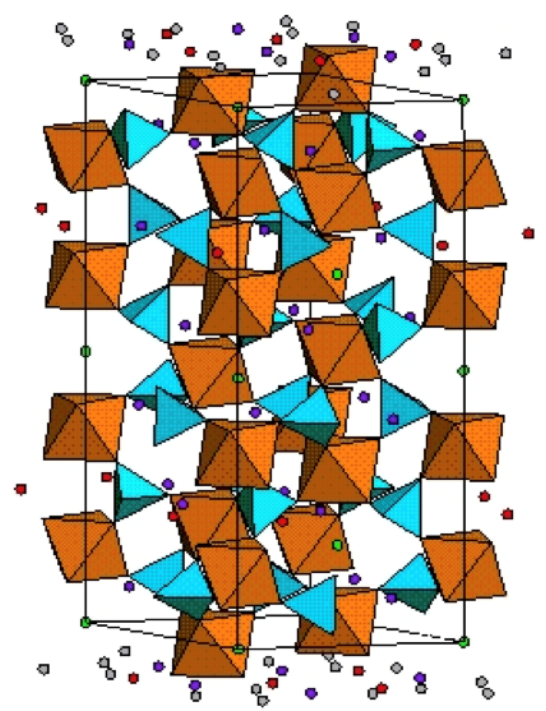

Figure 2.4 Structure of NaSICON [19]

The use of NaSICON in NaS battery is mostly under scientific development at the current stage, yet its potential of being both an electrical separator and super ion conductor at a low temperature is very tempting and promising. 


\subsubsection{Anode}

In a NaS battery, the sodium electrode forms the anode electrode. The half reaction in the anode is

$$
2 N a \rightleftharpoons 2 N a^{+}+2 e^{-}
$$

where the forward reaction is for discharging and the backward reaction is for charging.

There are two requirements for satisfactory operation of the sodium electrode: (1) the molten sodium metal must be kept in contact with the whole of the solid electrolyte surface during charge and discharge, and (2) there must be little or no interfacial polarization at the surface of the solid electrolyte.

A sodium reservoir and gravity feed of sodium is often used in order to physically maintain liquid sodium in contact with the whole surface of the electrolyte. This method is applied when increased height is not critical, such as applying to load levelling batteries. There are other ways to satisfy the first criteria, such as the use of a capillary wick system for electric vehicle applications.

Interfacial polarization can severely affect cell performance, such as inducing rapid resistance rise with cycling and asymmetry of cell resistance. Purity of the sodium used in the anode is usually the main reason that could cause this phenomenon. For betaalumina cells, the purity of alpha-alumina may also cause the occurrence of interfacial polarization. Thus, purity of the substances must be controlled accordingly. [10] 


\subsubsection{Cathode}

The half reaction in the cathode of the NaS battery is

$$
2 N a^{+}+x S+2 e^{-} \rightleftharpoons N a_{2} \mathrm{~S}_{x}
$$

or

$$
x S+2 e^{-} \rightleftharpoons S_{x}^{2-}
$$

where the forward reaction is for discharging and the backward reaction is for charging.

As can be seen from the half reaction, in the sulfur electrode elemental sulfur is reduced to sodium polysulfides on discharge and reformed by oxidation of these compounds on charge. At the operation temperature of 300 to $350^{\circ} \mathrm{C}$, the elemental sulfur is a viscous liquid and, because of its high electrical resistivity, an electronic insulator [20]. Since the electron transfer necessary for electrochemical reaction requires an electronic conductor that must not react with sulfur and the solid electrolyte as well, carbon is invariably used as electron conductor. Carbon felt or mat is often used as the matrix in the sulfur electrode and this is available in various resistivities.

Studies of the polysulfides [21] [22] [23] [24] [25]indicate that the melting point of $\mathrm{Na}_{2} \mathrm{~S}$ and $\mathrm{Na}_{2} \mathrm{~S}_{2}$ are about $1000^{\circ} \mathrm{C}$ and $480{ }^{\circ} \mathrm{C}$ respectively, indicating that they are at solid state in the range of operation temperature. The sodium polysulfide during battery operation usually form $\mathrm{Na}_{2} \mathrm{~S}_{x}$ with x ranging from 2 to 5 . At the beginning of a discharge process, sulfur is first reduced to $\mathrm{Na}_{2} \mathrm{~S}_{5}$. As discharge goes on, $\mathrm{Na}_{2} \mathrm{~S}_{4}$ and $\mathrm{Na}_{2} \mathrm{~S}_{3}$ appear and they are all in liquid forms. $\mathrm{Na}_{2} \mathrm{~S}_{2}$ usually appears last in a discharge process and it usually appears as solid in the cathode. 
The sodium polysulfides are extremely corrosive melts and selection of material for the current collector of the cathode requires some care. In batteries with beta-alumina electrolyte, aluminum can be used. However as this forms a film of insulating aluminum sulfide, it must be coated with other material.

For central sodium batteries in the aforementioned sections, where the cell case is also the current collector, aluminum is less favorable because of its relatively low melting point. Taking aluminum as the collector could compromise cell integrity in the case of cell failure occurrence. For these batteries, steel cases with some kind of protective coating are generally used. [10]

\subsection{Literature Review on Modeling}

$\mathrm{NaS}$ battery modeling is a very general term which may refer to many different things depending on the researchers from various groups. The models can be classified according to the dimensions of a cell model, namely zero-, one-, two- and threedimensional models. One-dimensional to three-dimensional models involves differential equations including respective special directions, where the details at small scales can be considered. Zero-dimensional models, however, consist of some global parameters in an integral sense. In other words, "lumped" models are developed in zero-dimensional view in order to reduce calculation time on simulation. Several one dimensional models were used to study NaS battery under different approaches.

Gibson, 1973 [26], developed a one dimensional NaS battery model where the distribution of potential in a homogeneous porous carbon electrode filled with molten sulfur / sodium polysulfide was given. The spatial distribution was shown to depend on the relative electrical resistivity of the melt and the carbon matrix, as well as the electrode thickness. 
A further development on the potential distribution model for rechargeable sulfur electrodes was conducted by Breiter and Dunn, 1979 [27]. Since the satisfactory rechargeability of a $\mathrm{NaS}$ battery based on an electronic resistance inside the carbon matrix can be mostly analyzed in terms of influence of potential distribution, the study was crucial to the long-term cell performance analysis. The result showed that placing the carbon mat adjacent to the beta-alumina electrolyte compelled all the current to be carried by the mat, and effectively suppression of sulfur formation at the beta-alumina interface was observed.

Wada, 1987 [28], made some study on the effect of a "dual mat" on the rechargeability of a NaS battery. "Dual mat" refers to a thin resistive porous mat between the solid electrolyte and conductive porous mat that fills the rest of the sulfur electrode. The study showed the "dual mat" can increase the recharge-discharge depth of the cell, and has almost the same energy efficiency as that of the homogeneous porous mat electrode.

Kao and Wayner [29] treated the reaction process with a time-dependent model which took the spatial variation of the sulfur molar fraction into account. This model is more realistic than the Gibson model. However, since the model is one-dimensional, it is impossible to estimate axial or circumferential non-uniformities which are frequently observed in the actual cell.

In order to study electrochemical reactions in porous sulfur electrodes of vertically supported sodium sulfur cells that are observed to have not only radial but also axial non-uniformity, numerous two-dimensional models were conducted in the literature.

A two-dimensional and two-component (ionic and electronic) conduction model is derived by Kawamoto and Wada, 1987 [30], to solve the problem numerically with finite element method. The results of calculations confirmed that the axially non-uniform distribution of the melt density causes the axial non-uniformity of the reaction rate. The 
authors also predicted that a modified sulfur electrode in which a mat of intermediate resistance being placed at the upper part of the electrode in addition to a porous mat of high resistance placed at the solid electrolyte surface would be capable of making the reaction rate uniform. Kawamoto continued the research in inhomogeneous twodimensional and two-component model and had some new result in 1989 [31]. It was shown that the dual mat electrode with the radially oriented fiber mat is preferable for realizing the high sulfur utilization and energy efficiency, and the sulfur electrode should be designed and manufactured so as to eliminate voids to suppress the degradation of the beta"-alumina and corrosion of the metal container, the rise of the cell resistance, and the decrease of the sulfur utilization.

\subsection{Summary}

Many modeling approaches can be found in literature, though most of which are one-dimensional or two-dimensional, with either homogeneous or inhomogeneous composition of sodium polysulfide in the electrode. Those models showed details of how a NaS battery works. Some research even went into deeper details when developing three-dimensional models. Although the more dimensionality a model has, the more details it would be able to obtain, the computational time needed for multi-dimensional model simulations is proportional to the details expected. A zero-dimensional transient model, on the other hand, has the advantage of very fast turnaround. Transients should rightly refer to the time of changes in temperature and species concentration, as well as the changes in voltage and current density within electrodes. In the current study, all these capabilities have been implemented in the lumped computational model of a $\mathrm{NaS}$ battery. 


\section{Chapter 3}

\section{Computational Model}

\subsection{Introduction}

The governing equations for the simulation of lumped model of the NaS battery are presented in this chapter. They are conservation of species, conservation of charge and conservation of energy equations. The equations are integral analysis of the basic physical laws, and the numerical method for the computational model is introduced in the last section.

The main idea of the lumped model is to take control volumes of the whole anode, cathode and electrolyte, respectively, with proper interaction among them. In other words, three control volumes are considered in each battery cell, as shown in Fig 3.1.

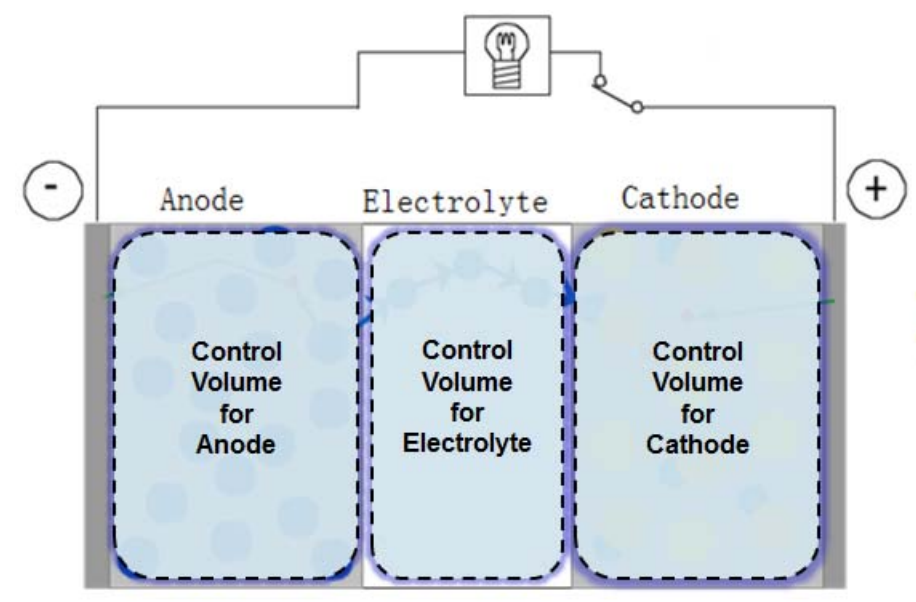

Figure 3.1 Control volumes used for lumped model of NaS battery 
The calculated Biot number for the battery under consideration is around $10^{-3}$ to $10^{-4}$, much smaller than 0.1 , which indicates that thermal performance of the NaS battery can be simulated using the lumped method with little error.

The following sections explain the details of the set of conservation equations in a discharge process. Since the equations for charging are very similar, they are summed up at the end of each section.

\subsection{Conservation of Species}

The general equation for conservation of species for a control volume can be written as

$$
\frac{d m_{s}}{d t}=\dot{m}_{s}^{\text {in }}-\dot{m}_{s}^{\text {out }}+\dot{m}_{s}^{\text {prod }}-\dot{m}_{s}^{\text {used }}
$$

Here $m$ and $t$ denote mass and time respectively, $s$ represents different species and $\dot{m}_{s}^{\text {in }}$ and $\dot{m}_{s}^{\text {out }}$ denote the mass flow rate of the species. Rate of consumption and rate of production of each species is denoted by $\dot{m}_{S}^{\text {used }}$ and $\dot{m}_{s}^{\text {prod }}$. These rates include the flux of reactants that take part in electrochemical reactions and across the solid electrolyte interfaces. Electrons are not discussed here, owing to the fact that they have little influence on the mass conservation results compared to the chemical species.

Based on the half reaction $2 \mathrm{Na} \rightleftharpoons 2 \mathrm{Na}^{+}+2 e^{-}$in the anode, it can be seen that for the discharge process with sodium refill, the only species coming into and going out of the anode side is sodium and sodium ion respectively, while sodium ion is the only substance that produced from sodium. Thus the equation for conservation of species in the anode is written as 


$$
\begin{gathered}
\frac{d m_{N a}}{d t}=\dot{m}_{N a}^{i n}-\dot{m}_{N a}^{\text {used }} \\
\frac{d m_{N a^{+}}}{d t}=-\dot{m}_{N a}^{\text {out }}+\dot{m}_{N a^{+}}^{p r o d} \\
\frac{d n_{N a}^{u s e d}}{d t}=\frac{d n_{N a^{+}}^{p r o d}}{d t}
\end{gathered}
$$

Here $n$ denotes number of moles. Taking account of the fact that the metallic bond loosened in molten state, it can be assumed that the anode is comprised of sodium ion only. Then, the above equations for anode can be simplified to

$$
\left(\frac{d m_{N a^{+}}}{d t}\right)_{\text {anode }}=\left(-\dot{m}_{N a^{+}}^{\text {out }}\right)_{\text {anode }}
$$

For the solid electrolyte, since no overall reaction occurs in the control volume the amount of sodium ion coming into the control volume equals to the amount going out. The conservation of species equation for electrolyte is simplified to

$$
\left(\dot{m}_{N a^{+}}^{\text {in }}\right)_{\text {electrolyte }}=\left(\dot{m}_{N a^{+}}^{\text {out }}\right)_{\text {electrolyte }}
$$

The half reaction in the cathode is $2 \mathrm{Na}^{+}+x \mathrm{~S}+2 e^{-} \rightleftharpoons \mathrm{Na}_{2} \mathrm{~S}_{x}$ which is the most complicated of the three control volumes in the lumped model. The number of moles of sulfur $x$ in polysulfides is not determined but they can be taken as one term $S_{x}^{2-}$. Since the only substance coming into the cathode is sodium ion, and nothing goes out of the control volume, the conservation of species equation for sulfur become 


$$
\begin{gathered}
\frac{d m_{S}}{d t}=\dot{m}_{S}^{\text {in }}-\dot{m}_{S}^{\text {used }} \\
\dot{m}_{N a^{+}}^{\text {in }}=\dot{m}_{N a^{+}}^{\text {used }}
\end{gathered}
$$

When sulfur is not refilled in the electrode, the first term on the right hand side becomes zero, which yields the only equations that matter being those related to reaction balance.

$$
\begin{gathered}
\left(\frac{d n_{S}}{d t}\right)_{\text {cathode }}=\left(\frac{x}{2} \frac{d n_{N a^{+}}}{d t}\right)_{\text {cathode }} \\
\left(\frac{d n_{N a_{2} S_{x}}}{d t}\right)_{\text {cathode }}=\left(-\frac{1}{2} \frac{d n_{N a^{+}}}{d t}\right)_{\text {cathode }}
\end{gathered}
$$

When considering the conservation of species among all three control volumes, the amount of sodium ion leaving the anode equals to that amount entering the solid electrolyte, and the amount of sodium ion leaving the electrolyte equal to that entering the cathode to react with sulfur. The relations are given by

$$
\begin{gathered}
\left(\dot{m}_{\mathrm{Na} a^{+}}^{\text {out }}\right)_{\text {anode }}=\left(\dot{m}_{\mathrm{Na} a^{+}}^{\text {in }}\right)_{\text {electrolyte }} \\
\left(\dot{m}_{\mathrm{Na}}^{\text {out }}\right)_{\text {electrolyte }}=\left(\dot{m}_{\mathrm{Na} a^{+}}^{\text {in }}\right)_{\text {cathode }}
\end{gathered}
$$

Substituting Eq. (3.2.6) into above two equations yields 


$$
\dot{m}_{N a^{+}}=\left(\dot{m}_{N a^{+}}^{\text {out }}\right)_{\text {anode }}=\left(\dot{m}_{N a^{+}}^{\text {in }}\right)_{\text {cathode }}
$$

Eq. (3.2.13) indicates the amount of sodium ion leaving the anode equals to that entering the cathode. In this way, Eq. (3.2.9) and Eq. (3.2.10) can be written as

$$
\begin{gathered}
\frac{d n_{S}}{d t}=\frac{x}{2} \frac{d n_{N a^{+}}}{d t} \\
\frac{d n_{\mathrm{Na}_{2} S_{x}}}{d t}=-\frac{1}{2} \frac{d n_{N a^{+}}}{d t}
\end{gathered}
$$

According to Faraday's law of electrolysis, the mass of a substance altered at an electrode during electrolysis is directly proportional to the quantity of electricity transferred at that electrode. This can be expressed as

$$
n=\frac{I}{z F} t
$$

Here, $\mathrm{n}$ is the moles of substance liberated in an electrolysis, $I$ denotes the current, $t$ denotes the time, $F$ is the Faraday constant and $z$ is the valency number of ions of the substance (electrons transferred per ion).

In this way, applying Faraday's law to the half reaction in anode gives

$$
-\frac{d\left(n_{N a^{+}}\right)}{d t}=\frac{I_{F}}{1 \cdot F}
$$

Since $I=I_{F}$, the faradaic current, this equation can be also written as 


$$
\frac{d\left(n_{\mathrm{Na}^{+}}\right)}{d t}=-\frac{I_{F}}{F}
$$

Substituting Eq. (3.2.18) into Eq. (3.2.14) and Eq. (3.2.15) gives

$$
\begin{aligned}
& \frac{d\left(n_{S}\right)}{d t}=-\frac{x}{2} \frac{I_{F}}{F} \\
& \frac{d\left(n_{N a_{2} S_{x}}\right)}{d t}=\frac{1}{2} \frac{I_{F}}{F}
\end{aligned}
$$

Eq. (3.2.18) to Eq. (3.2.20) are the final form of the equations for conservation of species in the process of discharge. For the charge process, these equations are also valid, since the only difference is the reversed reactions that take place in both anode and cathode.

\subsection{Conservation of Charge}

The general equation for conservation of charge is often written as

$$
\frac{\partial \rho}{\partial t}+\vec{\nabla} \cdot \vec{J}=0
$$

The term on the left is the rate of change of the charge density $\rho$ at a point. The term on the right is the divergence of the current density $J$ (charge per unit area per unit time). The equation indicates that the only way for the charge density to change is for a current of charge to flow into or out of a differential control volume. 
Eq. (3.3.1) is written in differential form. It can also be written in integral form for a control volume

$$
\frac{d q}{d t}=-\int_{V} \vec{\nabla} \cdot \vec{J} d V
$$

Here $V$ is the volume considered, and $q$ is for charge

$$
q=\int_{V} \rho d V
$$

The net current into a volume is

$$
I=-\oint_{S} \vec{J} \cdot \vec{n} d A
$$

where $S=\partial V$ is the boundary of $V$ oriented by outward-pointing normals, and $n d A$ is the outward pointing normal of the boundary $\partial V$. Here $J$ is the current density at the surface of the volume.

From Gauss's theorem

$$
\oint_{A} \vec{J} \cdot \vec{n} d A=\int_{V} \vec{\nabla} \cdot \vec{J} d V
$$

The integral form of the conservation of charge, Eq. (3.3.2), can then be written as

$$
\frac{d q}{d t}=-\oint_{S} \vec{J} \cdot \vec{n} d A
$$


or

$$
\frac{d q}{d t}=\sum_{V} I
$$

For the process of discharge in the anode, there is current entering the control volume in forms of flowing electrons, and current leaving in forms of flowing sodium ions at the same time.

Both electrons and ions are going out of the control volume of anode, but the direction of current is the opposite of the flowing direction of electrons. Hence, the equation for conservation of charge in the anode is

$$
\left(\frac{d q}{d t}\right)_{\text {anode }}=\left(I_{e}\right)_{\text {anode }}+\left(I_{i}\right)_{\text {anode }}
$$

where $I_{e}$ refers to the electric current from electron flow, and $I_{i}$ refers to that of sodium ion. Here, $I_{e}>0$ and $I_{i}<0$

Inside the solid electrolyte, it is discussed in chapter 2 that no electrons are supposed to pass at working condition, which makes the only current travelling through the electrolyte comes from sodium ion. It is also shown from Eq. (3.2.6) in conservation of species that the amount of sodium ion entering and leaving the solid electrolyte is the same. Thus, the equation for electrolyte is

$$
-\left(I_{i}\right)_{\text {anode }}=\left(I_{i}\right)_{\text {cathode }}
$$

The cathode shares similar situation with that of the anode, although the current comes into the control volume of cathode are in forms of sodium ion flow and the current 
leaves the cathode are in forms of incoming electrons. The equation for the control volume of cathode is

$$
\left(\frac{d q}{d t}\right)_{\text {cathode }}=\left(I_{e}\right)_{\text {cathode }}+\left(I_{i}\right)_{\text {cathode }}
$$

where $I_{e}<0$ and $I_{i}>0$.

For simpler cases, charge carried by total electrons can be assumed to be the same as that carried by total ions at any moment of a charge or discharge processes, in other words, charge density at any control volume can be assumed to be constant

$$
\frac{d q}{d t}=0
$$

It would have looked as simple as anyone would hope it to be if the equation for conservation of charge were reduced to the extent that consists of only current from electrons and current from sodium ions. However, another factor is of great importance when considering conservation of charge. That is the double layer capacitance effect.

This electrical phenomenon appears at the interface between a metallic conductive electrode and an adjacent electrolyte. Along this boundary between two different phases two layers of ions with opposite polarity will arise if a voltage is applied. The complexity of the double layer capacitance effect will not be discussed further in the present work, though modeling for the phenomenon must be included.

From the works of $\mathrm{NaS}$ and similar battery modeling [27] [31] [28] [32], the double layer capacitance effect can be calculated with an additional term. The equation for the anode can then be adjusted to 


$$
\left(a_{\text {int }} C_{D L} V\right)_{\text {anode }} \frac{d}{d t}(\Delta \phi)_{\text {anode }}=I_{F}-I^{i}
$$

or

$$
\left(a_{\text {int }} C_{D L} V\right)_{\text {anode }} \frac{d}{d t}(\Delta \phi)_{\text {anode }}=I_{F}+I^{e}
$$

Here $a_{\text {int }}, C_{\mathrm{DL}}$ and $I_{F}$ are interface area density, double layer capacitance and the faradaic current, respectively. $\Delta \phi$ denotes the potential difference between electron and ion conducting phases, that is

$$
\Delta \phi=\phi^{e}-\phi^{i}
$$

where $\phi^{e}$ and $\phi^{i}$ represent electric potential for electron and ion conducting phase, respectively.

Similarly, the final equation for the cathode is adjusted accordingly to

$$
\left(a_{\text {int }} C_{D L} V\right)_{\text {cathode }} \frac{d}{d t}(\Delta \phi)_{\text {cathode }}=I_{F}+I^{i}
$$

or

$$
\left(a_{\text {int }} C_{D L} V\right)_{\text {cathode }} \frac{d}{d t}(\Delta \phi)_{\text {cathode }}=I_{F}-I^{e}
$$

Eq. (3.3.13) to Eq. (3.3.16) can also be applied to the process of charge. Since the reversed reactions take place in both anode and cathode, and only the current changes direction. 


\subsection{Conservation of Energy}

According to conservation of energy principle, energy can be neither created nor destroyed, but can change form. For instance chemical energy can be converted to kinetic energy in a chemical reaction. The general equation for conservation of energy for a control volume can be written as

$$
\frac{d E}{d t}=\left(\dot{m} c_{p}\right)^{\text {in }} T^{\text {in }}-\left(\dot{m} c_{p}\right)^{\text {out }} T^{\text {out }}+\dot{Q}^{\text {net }}+\dot{Q}^{\text {source }}
$$

Here $E$ denote the total energy of the control volume, $c_{p}$ refers to specific heat capacity and $\left(\dot{m} c_{p}\right)^{i n}$ and $\left(\dot{m} c_{p}\right)^{\text {out }}$ denote the energy brought into and taken out of the control volume by mass flow. Net heat change $\dot{Q}^{\text {net }}$ is due to conduction or convection from the walls of all sides, and heat source $\dot{Q}^{\text {source }}$ is calculated as the summation of heat change due to the electrochemical reactions, $\dot{Q}^{\text {react }}$, and ohmic loss due to electric current, $\dot{Q}^{\text {ohm }}$.

$$
\begin{gathered}
\dot{Q}^{\text {net }}=\sum_{j=n e i g h b o r} \frac{k A^{\text {cond }}}{l}\left(T_{j}-T_{p}\right)+h A^{\text {conv }}\left(T_{\infty}-T_{p}\right) \\
\dot{Q}^{\text {source }}=\dot{Q}^{\text {react }}+\dot{Q}^{\text {ohm }} \\
\dot{Q}^{\text {ohm }}=\frac{I_{F}^{2}}{\sigma} \frac{l_{\text {eff }}}{A_{e f f}}
\end{gathered}
$$


Here, $\mathrm{k}$ is the thermal conductivity, $A$ is the effective contact area between adjacent space, $l$ is the characteristic conduction length scale, $T_{j}$ and $T_{p}$ represent the temperature of the neighbor space and the local temperature of the control volume, $\sigma$ is the electrical conductivity, $A_{e f f}$ is the effective cross-section area of the conductor and $l_{e f f}$ is the effective length of the conductor. $\dot{Q}^{\text {react }}$ can be different due to different half reactions and will be dealt with in specific case.

During discharge process in the anode, the only substance leaving the control volume is sodium ion, and nothing goes into the control volume. Taking account of the fact that the metallic bond loosened in molten state, it can be assumed that the anode is comprised of sodium ion only, which makes the reaction term zero. Thus Eq. (3.4.1) for anode is adjusted to

$$
\frac{d\left(m c_{p} T\right)_{A}}{d t}=-\left(\dot{m} c_{p}\right)_{N a^{+}, A}^{o u t} T_{E}+\dot{Q}_{A}^{\text {ohm }}+\dot{Q}_{A}^{\text {net }}
$$

The term on the left hand side can be written as

$$
\frac{d\left(m c_{p} T\right)_{A}}{d t}=\left(m c_{p}\right)_{A} \frac{d T_{A}}{d t}+\left(c_{p} \mathrm{~T}\right)_{A} \frac{d m_{A}}{d t}
$$

The last term in Eq. (3.4.6) is related to the mass flow rate for anode

$$
\left(c_{p} T\right)_{A} \frac{d m_{A}}{d t}=-\left(\dot{m} c_{p}\right)_{N a^{+}, A}^{\text {out }} T_{A}
$$

Combining Eq. (3.4.5) to Eq. (3.4.7) gives the final equation for anode: 


$$
\left(m c_{p}\right)_{A} \frac{d T_{A}}{d t}=-\left(\dot{m} c_{p}\right)_{N a^{+}, A}^{o u t}\left(T_{E}-T_{A}\right)+\dot{Q}_{A}^{\text {ohm }}+\dot{Q}_{A}^{n e t}
$$

Since the solid electrolyte is thin and there is same amount of sodium ion going into and out of the control volume, Eq. (3.4.1) for electrolyte can be reduced to

$$
\left(m c_{p}\right)_{E} \frac{d T_{E}}{d t}=\dot{Q}_{E}^{\text {ohm }}+\dot{Q}_{E}^{n e t}
$$

In the cathode, sodium ions go into the control volume and nothing goes out, thus Eq. (3.4.1) for cathode becomes

$$
\frac{d\left(m c_{p} T\right)_{C}}{d t}=\left(\dot{m} c_{p}\right)_{N a^{+}, C}^{i n} T_{E}+\dot{Q}_{C}^{r e a c t}+\dot{Q}_{C}^{\text {ohm }}+\dot{Q}_{C}^{n e t}
$$

where

$$
Q_{C}^{\text {react }}=-\frac{I}{2 F} T_{C}\left(\bar{s}_{S_{x}^{2-}}-2 \bar{s}_{e^{-}}-x \bar{s}_{S}\right)
$$

Here, $\bar{s}$ is the molar entropy of each species.

Similar to the process for anode, the simplification of Eq. (3.4.10) gives

$$
\left(m c_{p}\right)_{C} \frac{d T_{C}}{d t}=\left(\dot{m} c_{p}\right)_{N a^{+}, C}^{i n}\left(T_{E}-T_{C}\right)+\dot{Q}_{C}^{r e a c t}+\dot{Q}_{C}^{\text {ohm }}+\dot{Q}_{C}^{\text {net }}
$$

Eq. (3.4.5) to Eq. (3.4.12) can be applied to the process of charge as well; the only difference is the reaction term, which can be expressed as 


$$
Q_{C}^{\text {react }}=-\frac{I}{2 F} T_{C}\left(2 \bar{s}_{e^{-}}+x \bar{s}_{S}-\bar{s}_{S_{x}^{2-}}\right)
$$

The outside wall temperature change involves heat conduction from the cathode, $\dot{Q}^{\text {cond }}$, and free convection with the ambient air, $\dot{Q}^{\text {conv }}$.

$$
\begin{gathered}
\left(m c_{p}\right)_{\text {wall }} \frac{d T_{\text {wall }}}{d t}=\dot{Q}_{\text {wall }}^{\text {cond }}+\dot{Q}_{\text {wall }}^{\text {conv }} \\
\dot{Q}_{\text {wall }}^{\text {cond }}=(k A)_{\text {wall }}^{\text {cond }} \frac{\left(T_{j}-T_{\text {wall }}\right)}{l_{c h}} \\
\dot{Q}_{\text {wall }}^{\text {conv }}=h_{\text {air }} A_{\text {wall }}^{\text {conv }}\left(T_{\infty}-T_{\text {wall }}\right) \\
l_{c h}=\frac{\left(\delta_{j}+\delta_{\text {wall }}\right)}{2}
\end{gathered}
$$

Where, $j$ refers to the neighboring compartment, and $l_{c h}$ is the characteristic length which is taken as sum of half the thickness, $\delta$, of the wall and neighboring compartment. 


\subsection{Numerical Method}

From conservation of species and conservation of charge, a zero-dimensional lumped model for electric simulation can be achieved.

Eq. (3.2.18) to Eq. (3.2.20), Eq. (3.3.13) and Eq. (3.3.16) forms a set of simultaneous equations for the unknown amount of substances $n_{N a^{+}}, n_{S}, n_{N a_{2} S_{x}}$, unknown current $I^{i}, I_{F}$, and unknown voltage difference $\Delta \phi$. In order to solve the six unknowns, one more equation is needed, which is the electrochemical relationship between the Faradaic current and voltage difference. This equation together with other electrochemical relationships, consisting of numerous of physical parameters, is the key to the principle of a NaS battery and it will be elucidated in Chapter 4 .

Initial values of above six unknown parameters as well as the cell voltage are input parameters for the model as initial condition. Euler method is used for Eq. (3.2.18) to Eq. (3.2.20), Eq. (3.3.13) and Eq. (3.3.16) in the present work. Iteration goes on as a time marching manner; properties required for solving the equations, such as fluid density and ionic conductivity, are calculated and updated as a function of time based on each species within each control volume.

A zero-dimensional lumped model for temperature simulation can also be achieved when combining the equations for conservation of species and conservation of charge.

For this thermal model, Eq. (3.2.18) to Eq. (3.2.20) and Eq. (3.4.8), Eq. (3.4.9) and Eq. (3.4.12) are the governing equations used on the time iteration. The unknowns for this model are substances $n_{N a^{+}}, n_{S}, n_{N a_{2} S_{x}}$ and temperatures $T_{A}, T_{E}, T_{C}$, and the six governing equations also apply Euler method to do the time iterations. The properties calculated and updated at each time level are electrical conductivity, calculated from the electric model, thermal conductivity and specific heat capacity at the cathode. 
An example of Euler method applied on the conservation of energy equation for anode is shown in Eq. (3.5.2). The governing equation, as discussed in the last section, is

$$
\left(m c_{p}\right) \frac{d T}{d t}=-\left(\dot{m} c_{p}\right)\left(T_{E}-T_{A}\right)+\dot{Q}
$$

Euler method gives

$$
\left(m c_{p}\right)^{n} \frac{T^{n+1}-T^{n}}{\Delta t}=-\left(\dot{m} c_{p}\right)^{n}\left(T_{E}-T_{A}\right)^{n}+\dot{Q}^{n}
$$

where the superscript $n$ denotes the parameter values at the old time level, and $n+1$ denotes the parameter values at the present time level. 


\section{Chapter 4}

\section{Electrochemical Model}

\subsection{Introduction}

In order to analyze the chemical energy changes throughout the chemical process involved in the operation of a NaS battery, the relationship between electric current and potential must be placed in a central position. Gibbs free energy plays a highly important role in thus relationship. It affects the voltage of a $\mathrm{NaS}$ battery, and such process involves fundamental electrochemical equations such as Nernst equation and Butler-Volmer equation. These concepts are elucidated in this chapter.

\subsection{Gibbs Free Energy and Nernst Equation}

Changes in Gibbs free energy of formation determine the energy released during a chemical process. The Gibbs function of formation, $\bar{g}$, is defined as

$$
\bar{g}=\bar{h}-T \bar{s}
$$

where $\bar{h}$ is enthalpy per mole, $T$ is temperature and $\bar{s}$ is entropy per mole. The Gibbs free energy of the standard state other than the standard state $\left(25^{\circ} \mathrm{C}\right.$ and $\left.1 \mathrm{~atm}\right)$ is found by adding the Gibbs free energy of the standard state with that of the specific Gibbs function of the state of interest as shown below

$$
\bar{g}_{f}=\bar{g}_{f}^{o}+\Delta \bar{g}_{f}
$$


where $\bar{g}_{f}^{o}$ is the absolute Gibbs energy at standard state and $\Delta \bar{g}_{f}$ is the change in Gibbs free energy of formation. This change can be defined as the difference of Gibbs free energy of formation between products and reactants in a chemical reaction. Applying this to the overall reaction of a $\mathrm{NaS}$ battery presented in Chapter 2:

$$
2 \mathrm{Na}+x \mathrm{~S} \rightleftharpoons \mathrm{Na} a_{2} \mathrm{~S}_{x}
$$

For the forward reaction, or the process of discharge, the change in Gibbs free energy of formation is

$$
\Delta \bar{g}_{f}=\left(\bar{g}_{f}\right)_{N a_{2} S_{x}}-2\left(\bar{g}_{f}\right)_{N a}-x\left(\bar{g}_{f}\right)_{S}
$$

Assuming the reaction is reversible, meaning that all the Gibbs free energy is converted into electrical energy, then the Gibbs free energy can be used to find the open circuit voltage of the NaS battery. If we designate $-e$ as the charge on one electron, and knowing that two electrons are produced during the overall reaction of a $\mathrm{NaS}$ battery, then the charge that is produced by the reaction is

$$
-2 N e=-2 F
$$

where $F$ is the Faraday constant which is the charge on one mole of electrons, and $N$ is Avogadro's number.

The electrical work done by the NaS battery in moving two electrons around the circuit is calculated by the product of charge and voltage, which is 
where $E$ is the voltage of the NaS battery.

Since the process is reversible then the electrical work done will be equal to the Gibbs free energy released, $\Delta \bar{g}_{f}$. Therefore, the above equation becomes

$$
\Delta \bar{g}_{f}=-2 F E
$$

when rearranged, yield

$$
E=\frac{-\Delta \bar{g}_{f}}{2 F}
$$

where $E$ is the electromotive force (EMF) or reversible open circuit voltage (OCV) for a $\mathrm{NaS}$ battery.

However, in the case of any chemical reaction the products and reactants have an associated chemical activity, often denoted as " $a$ ". This chemical activity of the products and reactants alters the Gibbs free energy equation, as shown in Eq. (4.2.9)

$$
\Delta \bar{g}_{f}=\Delta \bar{g}_{f}^{o}+R T \ln \left(\frac{a_{N a_{2} S_{x}}}{\left(a_{N a}\right)^{2}\left(a_{S}\right)^{x}}\right)
$$

Here, $a_{N a_{2} S_{x}}, a_{N a}$ and $a_{S}$ are the chemical activity for $\mathrm{Na}_{2} S_{x}, \mathrm{Na}$ and $\mathrm{S}$ respectively, and $R$ is the universal gas constant. 
The altered form of the Gibbs free energy equation given in Eq. (4.2.9) will affect the voltage of a fuel cell as well. Substituting Eq. (4.2.8) into Eq. (4.2.9) yields the wellknown Nernst equation

$$
E=\frac{-\Delta \bar{g}_{f}^{o}}{2 F}-\frac{R T}{2 F} \ln \left(\frac{a_{N a_{2} S_{x}}}{\left(a_{N a}\right)^{2}\left(a_{S}\right)^{x}}\right)
$$

or

$$
E=E^{o}-\frac{R T}{2 F} \ln \left(\frac{a_{N a_{2} S_{x}}}{\left(a_{N a}\right)^{2}\left(a_{S}\right)^{x}}\right)
$$

where $E^{o}$ is the EMF at standard condition. The voltage given in Eq. (4.2.11) is known as "Nernst potential".

The relation between chemical activities of all the species is often written in terms of molality, $\mathrm{b}$, which is defined as the amount of moles of solute, $n_{\text {solute }}$, divided by the mass of the solvent, $m_{\text {solvent }}$

$$
b=\frac{n_{\text {solute }}}{m_{\text {solvent }}}
$$

The relationship between chemical activity and molality is

$$
a_{i}=\gamma_{b, s} \frac{b_{s}}{b^{\theta}}
$$

Here, $\gamma_{b}$ is the activity coefficient for molality and is approximately 1 for the $\mathrm{NaS}$ battery case, although for materials other than sodium it is better to have further research 
on the coefficient value. $b^{\theta}$ is the standard molality, and the subscript $s$ refers to different species.

Substituting molality into Eq. (4.2.11) gives the final form of the equation for OCV of a NaS battery:

$$
E=E^{o}-\frac{R T}{2 F} \ln \left(\frac{b_{N a_{2} S_{x}}}{\left(b_{N a}\right)^{2}\left(b_{S}\right)^{x}}\right)
$$

Alternatively, the relation between chemical activities of all the species can also be written in terms of molar concentration, $\mathrm{c}$.

$$
a_{i}=\gamma_{c, s} \frac{c_{s}}{c^{\theta}}
$$

Here, $\gamma_{c}$ is the activity coefficient for concentration and, similar to $\gamma_{b}$, is assumed to be 1 for the NaS battery case. $c^{\theta}$ is the standard molar concentration, and the subscript $s$ refers to different species. Similar to molality, the Nernst equation can also be written in terms of molar concentration of all the species.

$$
E=E^{o}-\frac{R T}{2 F} \ln \left(\frac{c_{N a_{2} S_{x}}}{\left(c_{N a}\right)^{2}\left(c_{S}\right)^{x}}\right)
$$

\subsection{Various Losses or Overpotentials in a Battery}

The theoretical voltage of a $\mathrm{NaS}$ battery showed in the last section is never truly realized; sometimes it is not even reached when the OCV is measured. The reason for that lies in different kind of voltage losses across the anode and cathode. 
There are three common types of losses, which are activation losses, ohmic losses and mass transport/concentration losses. These losses each have their own way of affecting the theoretical voltage of a NaS battery.

\subsubsection{Activation Loss}

The activation loss occurs because the chemical process initially has not begun, thus activation energy is necessary to insure that the reaction tends toward the formation of sodium polysulfides and electricity, as opposed to the reverse.

This loss is often termed overpotential, and is essentially the voltage difference between the two terminals. There are some empirical equations that describe how the electrical current on an electrode depends on the electrode overpotential. Among those, the most famous are Butler-Volmer equation and Tafel equation, and the former is used in the present work on modeling of NaS battery.

The Butler-Volmer equation for anode and cathode can be expressed respectively as

$$
i_{F}=i_{o}\left[e^{\alpha_{A}^{a} F \eta_{A}}-e^{-\alpha_{A}^{c} F \eta_{A}}\right]
$$

and

$$
i_{F}=i_{o}\left[e^{\alpha_{C}^{a} F \eta_{C}}-e^{-\alpha_{C}^{c} F \eta_{C}}\right]
$$

Here, $i_{F}$ is the Faradaic current density, $i_{o}$ is the exchange current density, $F$ is the Faraday constant, and $\eta_{A}$ and $\eta_{C}$ are the overpotential for anode and cathode respectively. 
$\alpha_{A}^{a}$ and $\alpha_{A}^{c}$ denote the anodic transfer coefficient for anode and cathodic transfer coefficient for anode, respectively, and $\alpha_{C}^{a}$ and $\alpha_{C}^{c}$ denote the anodic transfer coefficient for cathode and cathodic transfer coefficient for cathode, respectively. It is usually assumed that

$$
\begin{aligned}
& \alpha_{A}^{a}=1-\alpha_{A}^{c} \\
& \alpha_{C}^{a}=1-\alpha_{C}^{c}
\end{aligned}
$$

Overpotentials $\eta_{A}$ and $\eta_{C}$ are expressed respectively as

$$
\eta_{A}=-0.5 O C V-\left(\phi_{A}^{e}-\phi_{A}^{i}\right)
$$

and

$$
\eta_{C}=0.5 O C V-\left(\phi_{C}^{e}-\phi_{C}^{i}\right)
$$

where the subscripts $A$ and $C$ denote anode and cathode respectively, and the superscripts $e$ and $i$ denote the potential for electron and ion respectively.

The exchange current density is the current in the absence of net electrolysis and at zero overpotential. In this study, exchange current density in the cathode is expressed differently between the process of discharge and charge.

For discharging $(\mathrm{I}<0)$, 


$$
i_{o}=i_{o}^{*} \frac{\left(y_{S}\right)^{m}}{1+\left(\frac{1}{y_{S}}\right)^{n}}=i_{o}^{*} \frac{y_{S}^{m+n}}{1+y_{S}^{n}}
$$

For charging $(\mathrm{I}>0)$,

$$
i_{o}=i_{o}^{*} \frac{\left(y_{\mathrm{Na}_{2} S_{x}}\right)^{m}}{1+\left(\frac{1}{y_{N a_{2} S_{x}}}\right)^{n}}=i_{o}^{*} \frac{y_{\mathrm{Na}_{2} S_{x}}^{m+n}}{1+y_{\mathrm{Na}_{2} S_{x}}{ }^{m}}
$$

where, $i_{o}^{*}$ is a reference current density, $y$ refers to mass fraction of different species, $m$ and $n$ are empirical model parameters.

Since activation potential, $\eta_{a c t}$, is termed overpotential, $\eta$. When rearranging Eq. (4.3.2), the Butler-Volmer equation can be expressed as

$$
\eta_{a c t}=\frac{2 \alpha R T}{n F} \sinh ^{-1}\left(\frac{i}{2 i_{o}}\right)
$$

\subsubsection{Ohmic Loss}

Another type of common loss is ohmic loss. Ohmic loses are prevalent in every electronic device, and NaS battery is no exception to this rule. This type of loss occurs because of the resistance to the flow of electrons in the solid electrolyte, the anode and cathode. This loss $V_{\text {ohm }}$, like all ohmic losses, is directly proportional to the current.

$$
V_{\text {ohm }}=I R_{o}
$$


where $R_{o}$ is the electrical resistance of the battery.

The resistance of the battery is calculated from the effective conductivity, $\sigma^{\text {eff }}$ at each control volume.

$$
\begin{gathered}
\sigma_{A}^{e f f}=\sigma_{N a} \\
\sigma_{E}^{e f f}=\sigma_{E} \\
\sigma_{C}^{e f f}=\varepsilon_{S}^{\beta} \sigma_{S}+\varepsilon_{N a_{2} S_{x}}^{\beta} \sigma_{N a_{2} S_{x}}+\varepsilon_{m e s h}^{\beta} \sigma_{m e s h}
\end{gathered}
$$

where $\varepsilon$ denotes the porosity or volume fraction of each substance, $\beta$ is the tortuosity factor, the subscript $A, E$ and $C$ denote anode, electrolyte and cathode, respectively, and the rest subscripts denote each species and the carbon mesh at the cathode electrode.

\subsubsection{Mass Transport/Concentration Loss}

The final type of common loss is the mass transport/concentration loss. This loss is the result of the effect of consuming a high concentration of either material at the anode and cathode. It essentially occurs because the NAS battery is using materials faster than it can be supplied [33].

This type of loss is also considered a Nernstian loss since the Nernst equation can be used to determine the change in Voltage. In the present zero-dimensional model, however, it is somewhat hard to track the mass transport within the control volume, thus limiting the actual simulation effectiveness of this kind of losses. In the current model, 
this concentration loss is not calculated. However, a model is proposed in Appendix I, which can be used for further study.

\subsection{Summary}

In this chapter, two key factors in the electrochemical concepts are mentioned and analyzed, which are OCV and loses. From Gibbs free energy and Nernst equation, the final form of OCV is deduced, shown as

$$
E=E^{o}-\frac{R T}{2 F} \ln \left(\frac{c_{N a_{2} S_{x}}}{\left(c_{N a}\right)^{2}\left(c_{S}\right)^{x}}\right)
$$

When loses are considered, together with the OCV, the total cell voltage $V_{\text {cell }}$ is calculated.

$$
V_{\text {cell }}=O C V-I R_{o}-\eta_{a c t}
$$

Although there are other loses such as the crossover/internal current losses which occur either when substance leaks though the electrode or electrons leak through the electrode, most common types of loses are discussed in the present work, and are simulated in the zero-dimensional lumped model of NAS battery. A more detailed model may be needed to take account of other loses in the battery. 


\section{Chapter 5}

\section{Application}

\subsection{Introduction}

It is important to verify and validate once a code is developed for a simulation. According to Institute of Electrical and Electronics Engineers (IEEE), the definition of verification is "The evaluation of whether or not a product, service, or system complies with a regulation, requirement, specification, or imposed condition. It is often an internal process. Contrast with validation." and validation is defined as "The assurance that a product, service, or system meets the needs of the customer and other identified stakeholders. It often involves acceptance and suitability with external customers." [34]

In short, verification can be expressed to answer "does the code solve the mathematical model correctly?" and validation to answer "does the simulation represent the reality accurately?" [35]

The processes of verification and validation of a code is usually done by comparing the results of the code with either experimental results or the results from another independent but verified model under the same set of operating conditions. However, due to limitations imposed by modeling assumptions, sometimes it may not be possible to exactly match all the conditions between the model and the experiments or between different models. It is imperative to match the independent parameters as much as possible in order to make a reasonable comparison.

The final objective of this research, as mentioned in Chapter 1, is to develop a zero-dimensional, transient, lumped model to simulate and assess the performance of $\mathrm{NaS}$ batteries. The model is derived from integral analysis of the transport of mass, energy and charge discussed in Chapter 3 and equations of the relationship between 
electric current and potentials discussed in Chapter 4. The verification and validation of the MATLAB computer program developed is presented in this chapter, as well as the details of the test cases and the performance results obtained for the simulations of $\mathrm{NaS}$ battery.

\subsection{Description of Test Cases}

The test case used here is an experimental case studied by Hiroyuki Kawamoto and Yasuji Kusakabe [1] which also includes some computational results from a twodimensional computational NaS battery model. In this case, the battery is tubular, and beta-alumina is used as the solid electrolyte. Inside the solid electrolyte is the anode, which is supplied as reservoir of sodium. Outside the solid electrolyte is the cathode, which is filled with graphite mat and sulfur. A schematic drawing of the battery used for experiments and calculations is shown in Fig 5.1. 


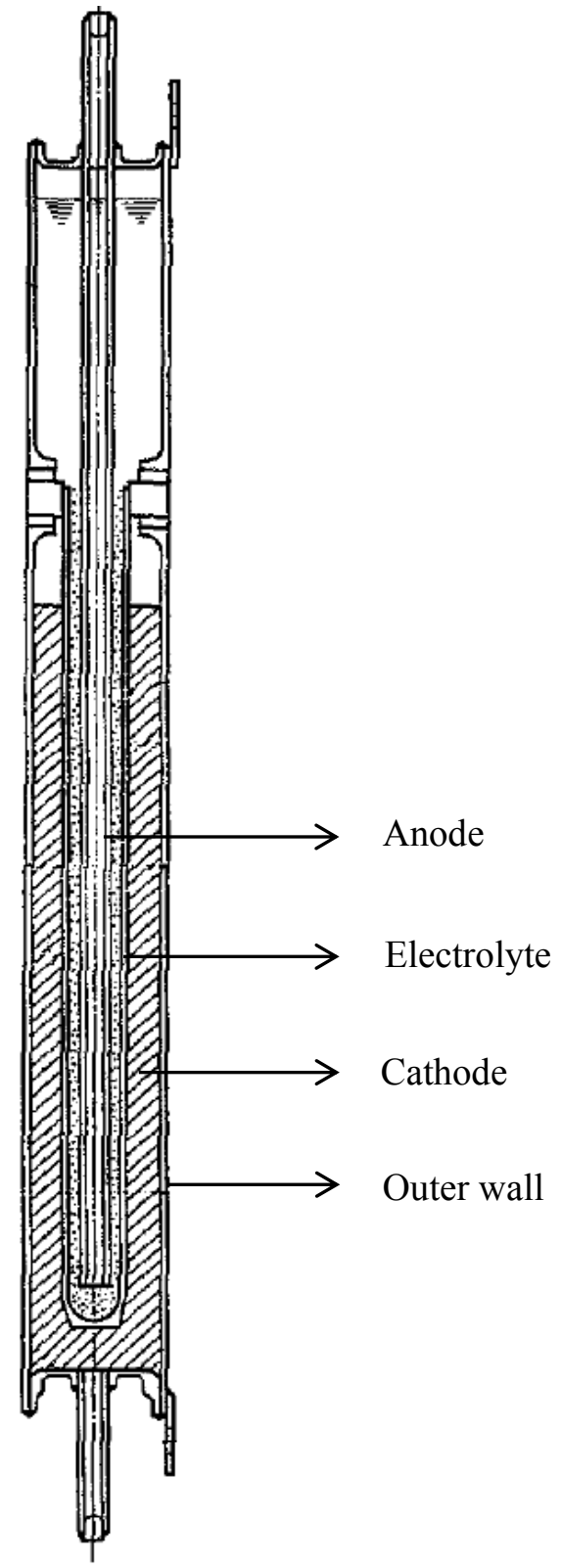

Figure 5.1 schematic drawing of the NaS battery [1] 
The dimensions of the NaS battery are as indicated in Table 5.1:

Table 5.1 Dimensions of the NaS battery

\begin{tabular}{|l|l|}
\hline Parameter & Value \\
\hline Beta-alumina solid electrolyte tube outer diameter $(\mathrm{mm})$ & 15 \\
\hline Beta-alumina solid electrolyte tube inner diameter $(\mathrm{mm})$ & 13.8 \\
\hline Beta-alumina solid electrolyte tube length $(\mathrm{mm})$ & 200 \\
\hline Effective and averaged surface area of the beta-alumina $\left(\mathrm{cm}^{2}\right)$ & 77 \\
\hline Battery tube outer diameter $(\mathrm{mm})$ & 32 \\
\hline Battery tube inner diameter $(\mathrm{mm})$ & 30 \\
\hline Battery tube length $(\mathrm{mm})$ & 300 \\
\hline Battery tube weight $(\mathrm{g})$ & 600 \\
\hline Sodium input weight $(\mathrm{g})$ & 58 \\
\hline Sulfur input weight $(\mathrm{g})$ & 100 \\
\hline
\end{tabular}

In the experiment from [1], the battery is designed for load leveling application, thus a standard charge/discharge time is designed to be $8 \mathrm{~h} / 8 \mathrm{~h}$, and the averaged current density at the beta-alumina is $78 \mathrm{~mA} / \mathrm{cm}^{2}$. The battery was set in a furnace, where the temperature variations within were less than $5^{\circ} \mathrm{C}$ at the battery operating temperature. The operation started at $325-335^{\circ} \mathrm{C}$ with the current density of $39 \mathrm{~mA} / \mathrm{cm}^{2}$, which was one half of the rated current density. After several cycles of the operation, the charge/discharge current density was then increased to $78 / 78 \mathrm{~mA} / \mathrm{cm}^{2}$. Stable performance was obtained during tens of rated cycles. Then, the operations under high current densities of $130 / 130 \mathrm{~mA} / \mathrm{cm}^{2}$ and 195/260 mA/cm ${ }^{2}$ were conducted. Open circuit time between charge/ discharge and discharge/charge operations was set to $1 \mathrm{~min}$ to measure the OCV. 
The code developed in this study involves numerous physical properties. The key physical properties used in the lumped model are indicated in Table 5.2, while the full list of properties and factors used in the code are indicated in APPENDIX II. Physical properties of parameters under 300 to $400^{\circ} \mathrm{C}$ are calculated at average temperature and kept constant for each substance in the present model since it has little change in the operating temperature. The values of density, ionic conductivity, thermal conductivity, specific heat capacity, thermal conductivity and entropy of sodium, sulfur, sodium polysulfide, graphite mat and beta-alumina in the code are obtained through literatures [21-23, 37-42].

Convective heat transfer coefficient, $h$, is calculated using the empirical equation from [36].

Table 5.2 Key properties at 300 to $400^{\circ} \mathrm{C}$ used in the $\mathrm{NaS}$ battery

\begin{tabular}{|l|l|l|l|}
\hline & $\begin{array}{l}\text { Electric conductivity } \\
(/ \Omega / \mathrm{m})\end{array}$ & $\begin{array}{l}\text { Specific heat capacity } \\
(\mathrm{J} / \mathrm{g} / \mathrm{K})\end{array}$ & $\begin{array}{l}\text { Thermal conductivity } \\
(\mathrm{W} / \mathrm{m} / \mathrm{K})\end{array}$ \\
\hline Sulfur & $5.0 \mathrm{e}-16$ & 0.71 & 0.205 \\
\hline $\mathrm{Na}_{2} \mathrm{~S}_{3}$ & $3.5 \mathrm{e}-5$ & 0.52 & 0.270 \\
\hline Sodium & $8.0 \mathrm{e} 6$ & 1.29 & 200 \\
\hline Graphite mat & $8.3 \mathrm{e} 4$ & 0.846 & 300 \\
\hline Beta-alumina & 20 & 0.90 & 2.50 \\
\hline
\end{tabular}

\subsection{Results and Discussion}

The transients of the cell voltage (voltage of the battery), OCV and temperature predicted by the zero-dimensional lumped model for $\mathrm{NaS}$ battery are compared to those from experiments and predicted by Kawamoto and Kusakabe [1] in Figs 5.2 through 5.4. In addition, a detailed analysis of the results from the lumped model is discussed. 
The cut-off voltages to stop charge/discharge operations were adjusted to $2.40 / 1.50 \mathrm{~V}$ for the current density of $130 / 130 \mathrm{~mA} / \mathrm{cm}^{2}$ in [1]. The same condition is implemented in the lumped model, so that a current of $130 \mathrm{~mA} / \mathrm{cm}^{2}$ is kept constant throughout the charge and discharge process, and when the cell voltage of $2.4 \mathrm{~V}$ is achieved the battery stops charging and begins discharging until $1.5 \mathrm{~V}$ is reached for the cell voltage.

In the charging process, after the cell voltage became gradually high in the consequence of an OCV increase, it became almost flat. Then the voltage increased rapidly high at the end of charge due to the formation of atomic sulfur at the interface between the sulfur electrode and solid electrolyte [1].

Cases of NaS battery running at $195 / 260 \mathrm{~mA} / \mathrm{cm}^{2}$ and $260 / 390 \mathrm{~mA} / \mathrm{cm}^{2}$ with the cut-off voltages of $2.60 / 1.20 \mathrm{~V}$ and $2.60 / 1.05 \mathrm{~V}$ respectively are also used to make comparisons between the model from the present work and that found in literature.

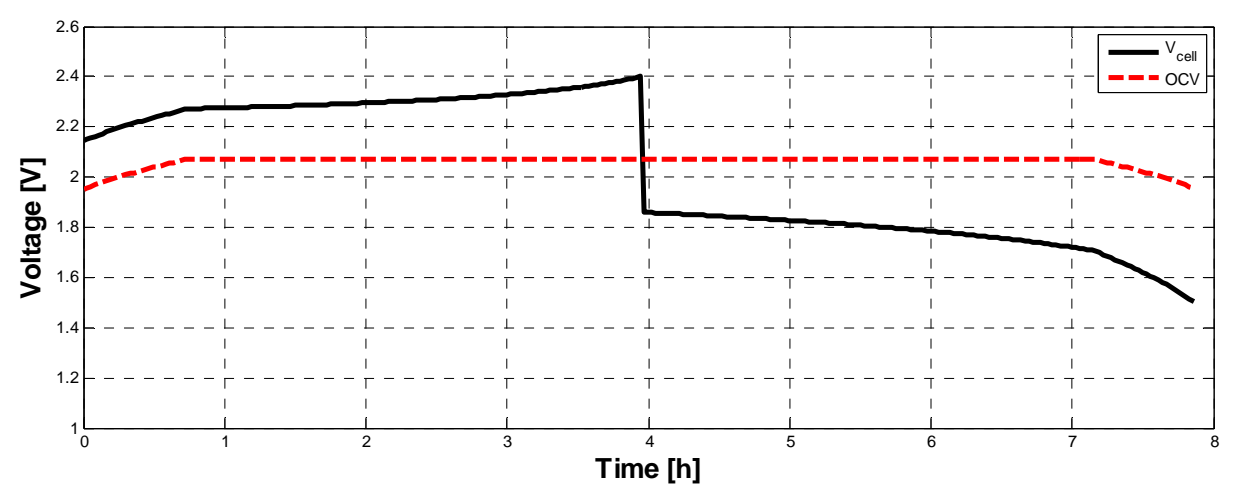

Figure 5.2 Voltage results at $130 / 130 \mathrm{~mA} / \mathrm{cm}^{2}$ charge/discharge from lumped model 


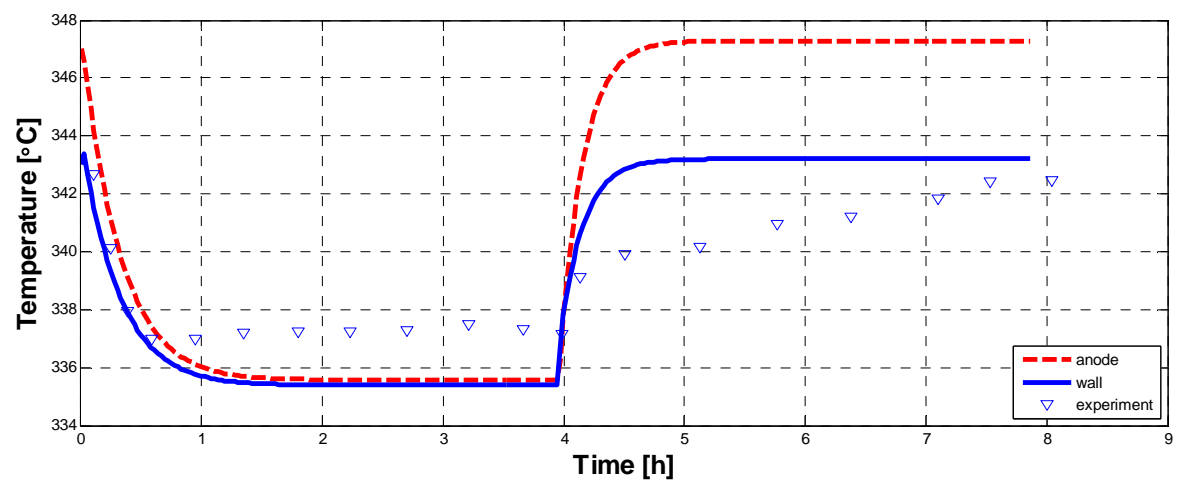

Figure 5.3 Temperature results at $130 / 130 \mathrm{~mA} / \mathrm{cm}^{2}$ charge/discharge from lumped model

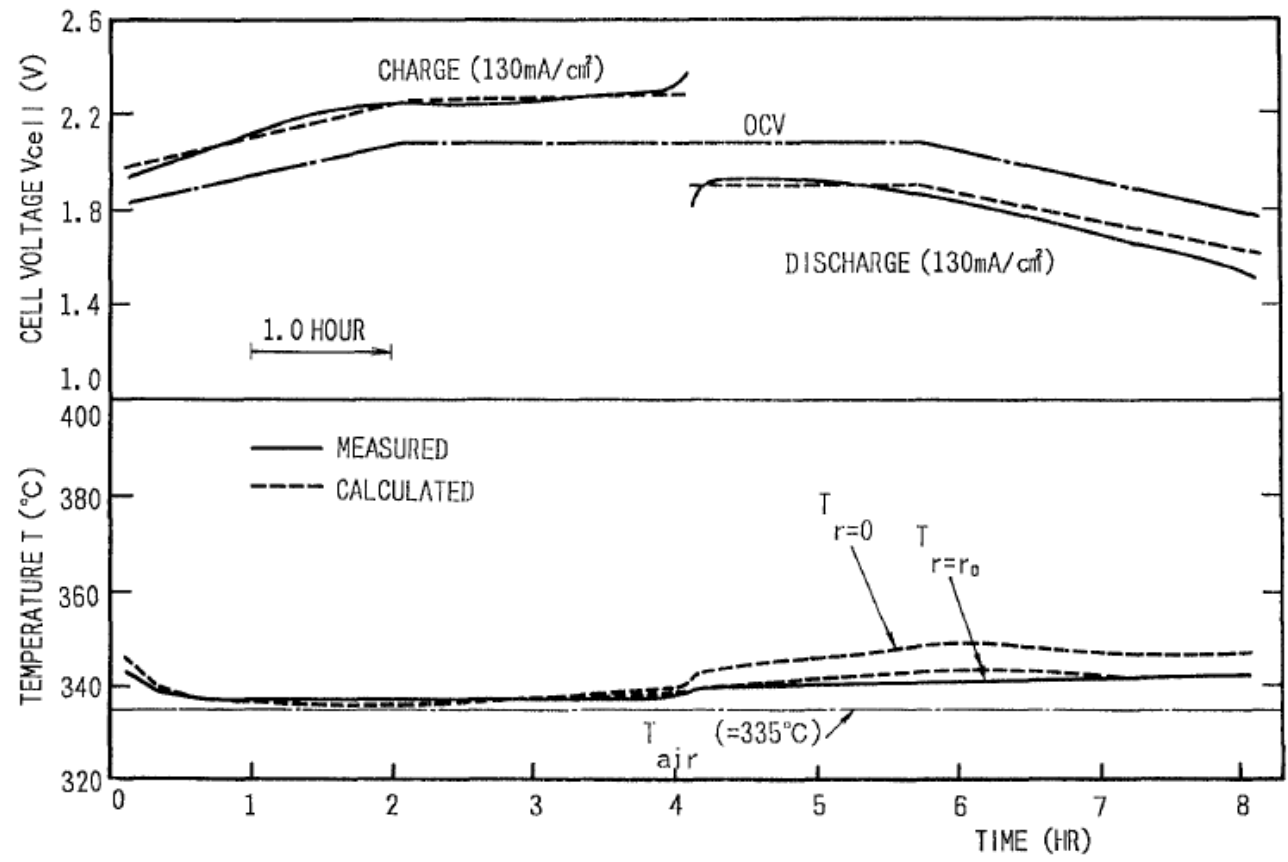

Figure 5.4 Results at 130/130 mA/ $\mathrm{cm}^{2}$ charge/discharge from [1]

Figs 5.2 to 5.4 shows the charge/discharge characteristics of the cell operated at $130 / 130 \mathrm{~mA} / \mathrm{cm}^{2}$ charge/discharge current density. Fig 5.2 and Fig 5.3 are the voltage 
and temperature results, respectively, from the simulation of the lumped model developed in this study, while Fig 5.4 shows the result from both experiments and computational model reported in [1].

In Fig 5.4, the calculated voltages agree qualitatively with measured ones, with somewhat large discrepancies exist at the end of the charging and the very beginning of discharging, which might result from the concentration polarization that is neglected in the model. The results from Fig 5.2 exhibit the same operation time and trend, and the $\mathrm{OCV}$ and cell voltage are consistent with that shown in the literature. The results from the lumped model even show a slightly better match to the experimental results. However, it should be noted that the concentration polarization is not included either in the lumped model.

The temperature curves from literature in Fig 5.4 depict the temperature calculated at the anode $(r=0)$ and at the outer wall of the cathode chamber $\left(r=r_{o}\right)$. The temperature obtained from experiment is also shown in Fig 5.4, which was measured from the outer wall as well. Temperature results in the Fig 5.3 exhibit the temperature calculated at anode and the outer wall from the lumped model. It can be seen from the comparison that the curves for anode and outside wall in Fig 5.3 also show good agreement with the experimental results from literature.

Fig. (5.5) to Fig. (5.7) exhibit the comparison between the lumped model results and those from the literature for the case of current density at $195 / 260 \mathrm{~mA} / \mathrm{cm}^{2}$ for charge/discharge, while Fig. (5.8) to Fig. (5.10) exhibit the ones at 260/390 mA/cm². 


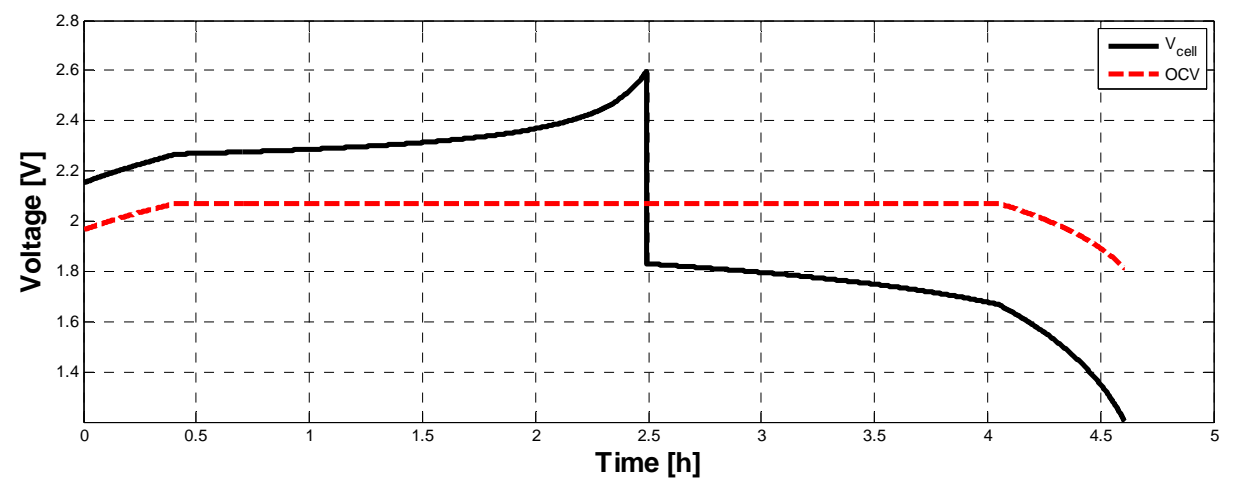

Figure 5.5 Voltage results at 195/260 mA/ $\mathrm{cm}^{2}$ charge/discharge from lumped model

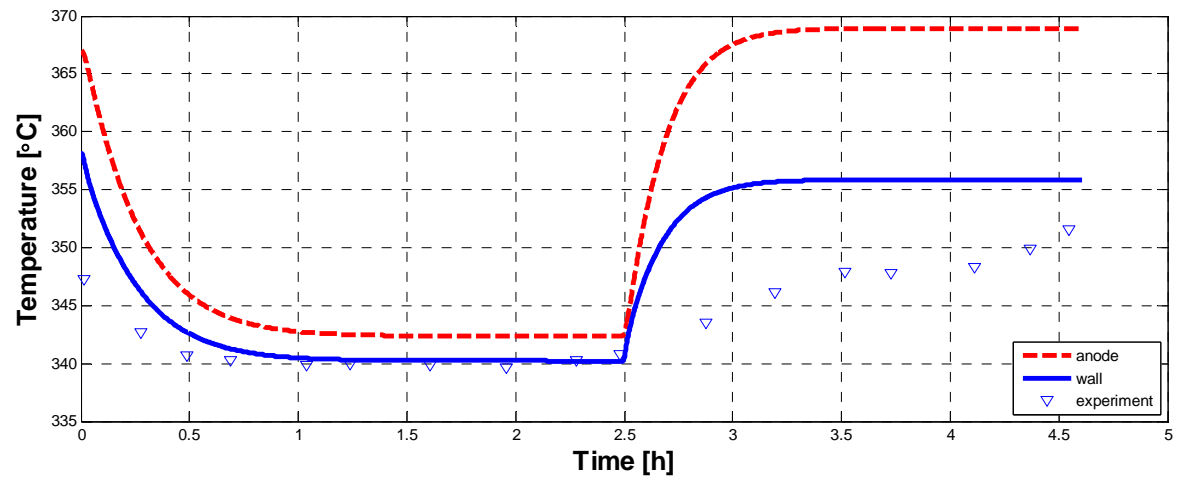

Figure 5.6 Temperature results at 195/260 mA/ $\mathrm{cm}^{2}$ charge/discharge from lumped model 


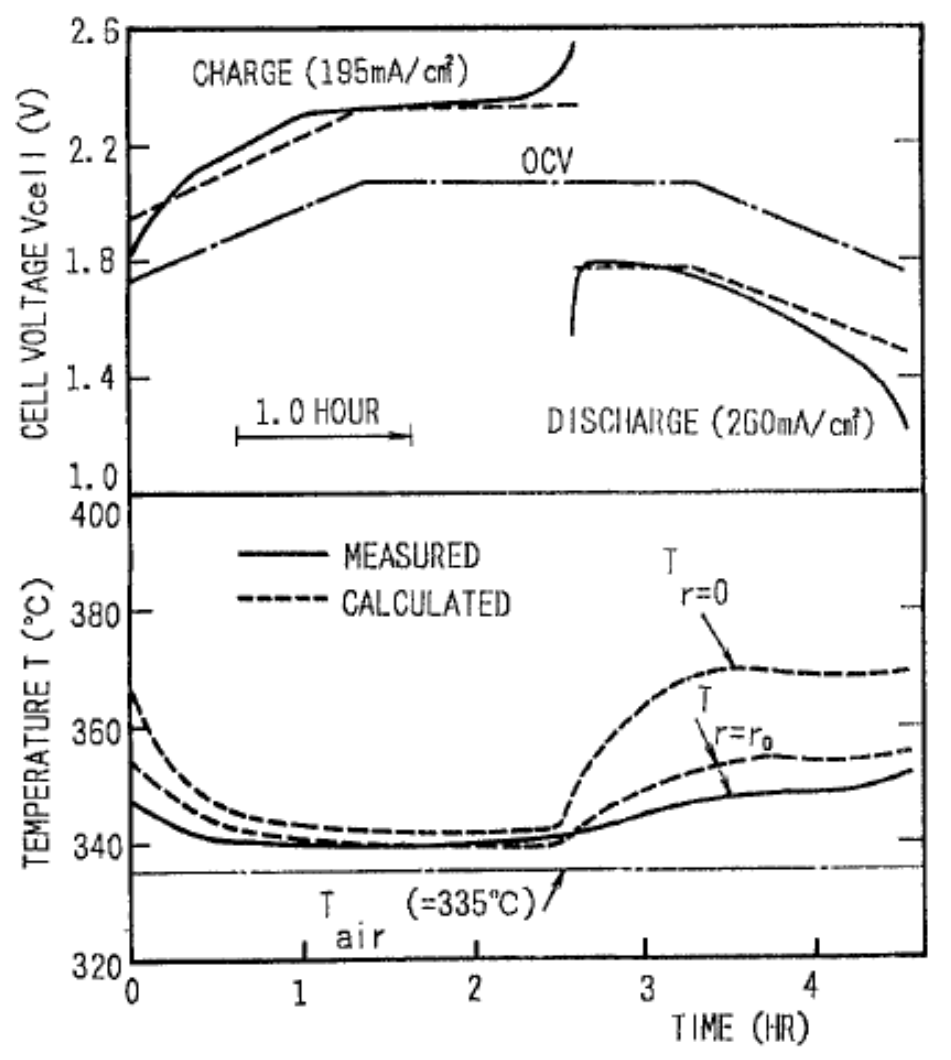

Figure 5.7 Results at 195/260 mA/ $\mathrm{cm}^{2}$ charge/discharge from [1]

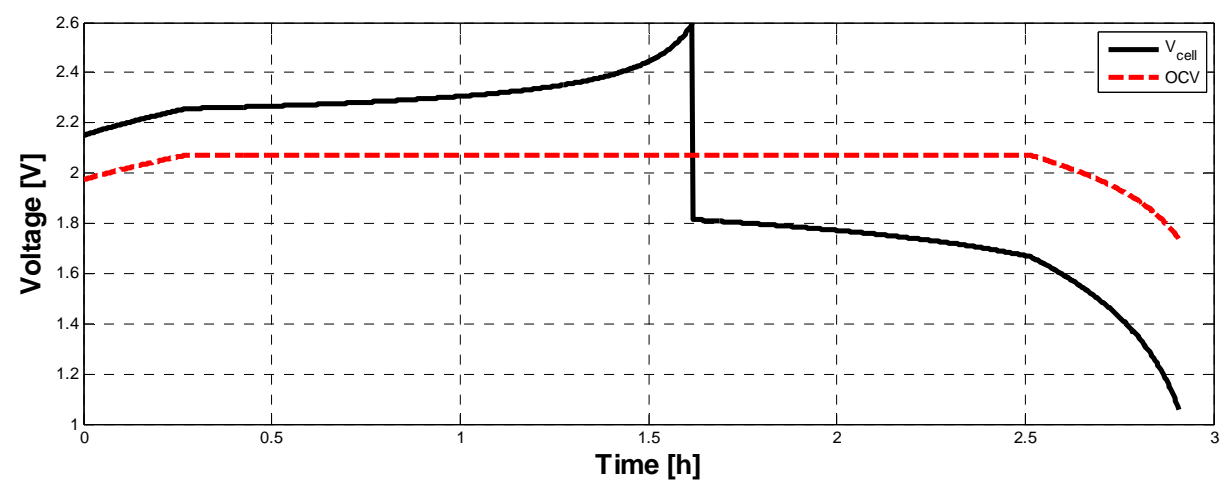

Figure 5.8 Voltage results at $260 / 390 \mathrm{~mA} / \mathrm{cm}^{2}$ charge/discharge from lumped model 


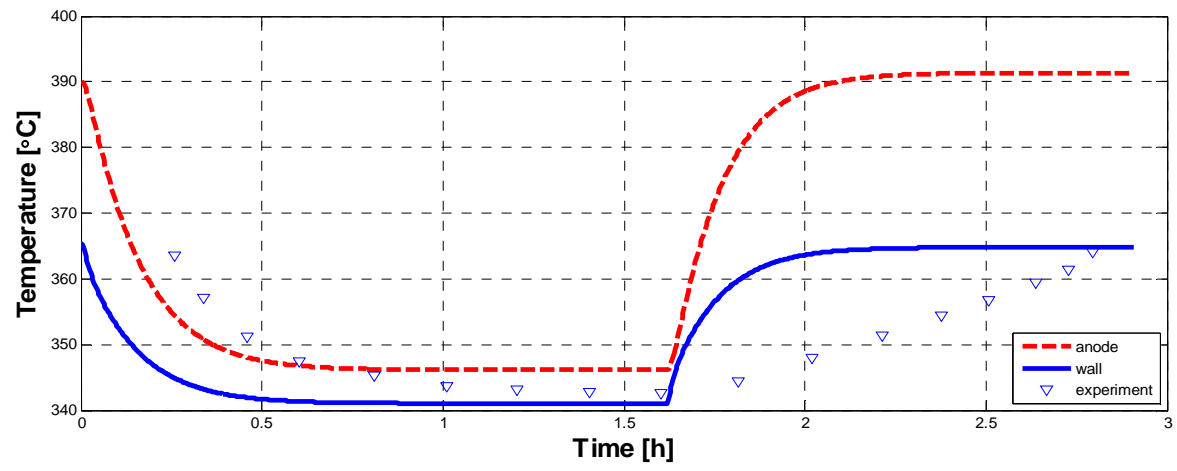

Figure 5.9 Temperature results at $260 / 390 \mathrm{~mA} / \mathrm{cm}^{2}$ charge/discharge from lumped model

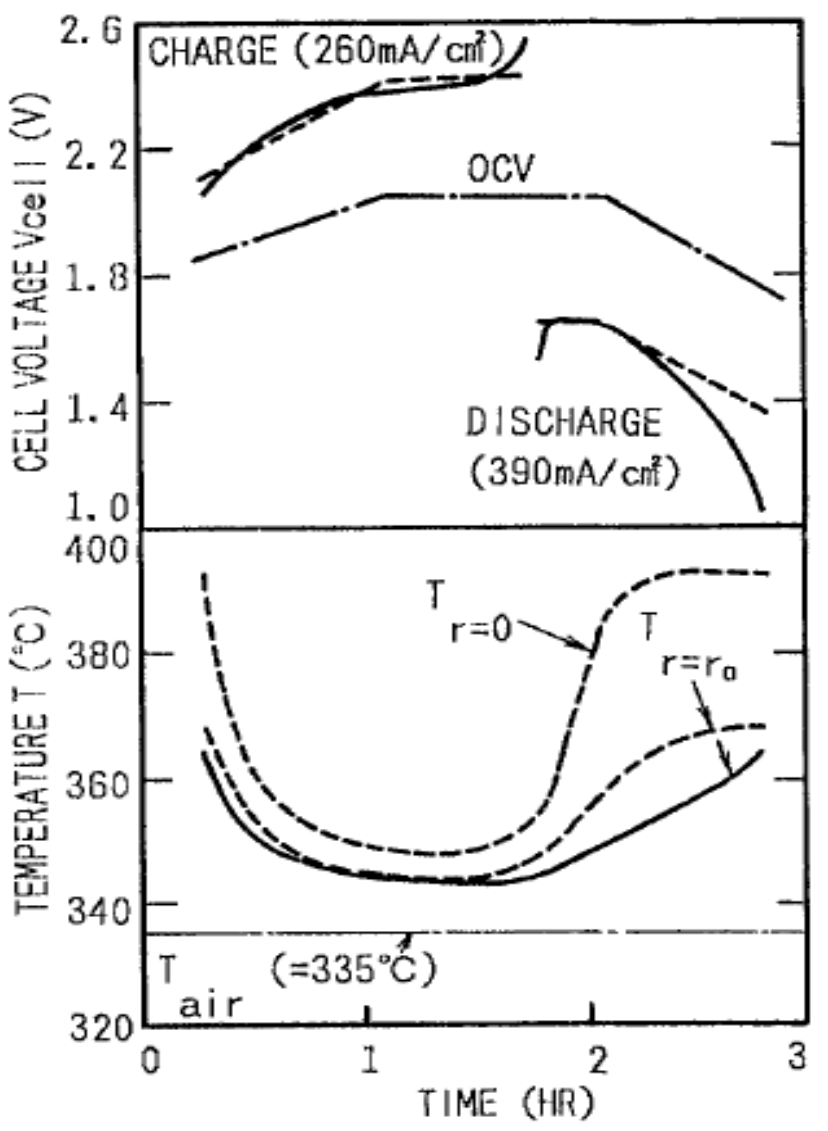

Figure 5.10 Results at 260/390 mA/ $\mathrm{cm}^{2}$ charge/discharge from [1] 54 
It can be seen from the comparisons above, that the lumped model predicted similar behavior, in the average sense, with those from the experiment and computational model in the literature, while there are also small differences in the details of the curves. This difference may results from neglecting of some minor factor when deducting the equations for conservation of energy, such as neglecting the ionization process between sodium and sodium ion. Further work is required to elucidate the factors that may be causing these differences.

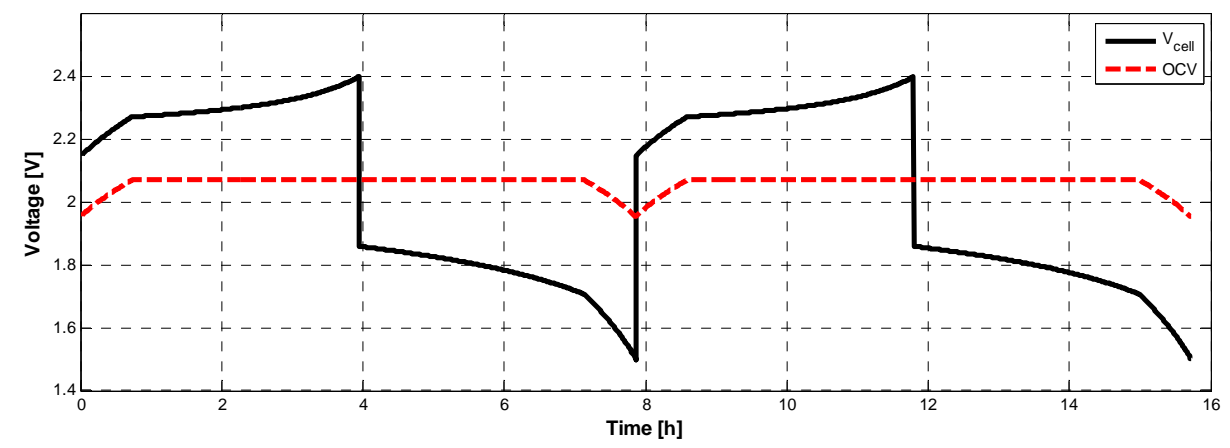

Figure 5.11 Voltage simulation running in cycles from lumped model

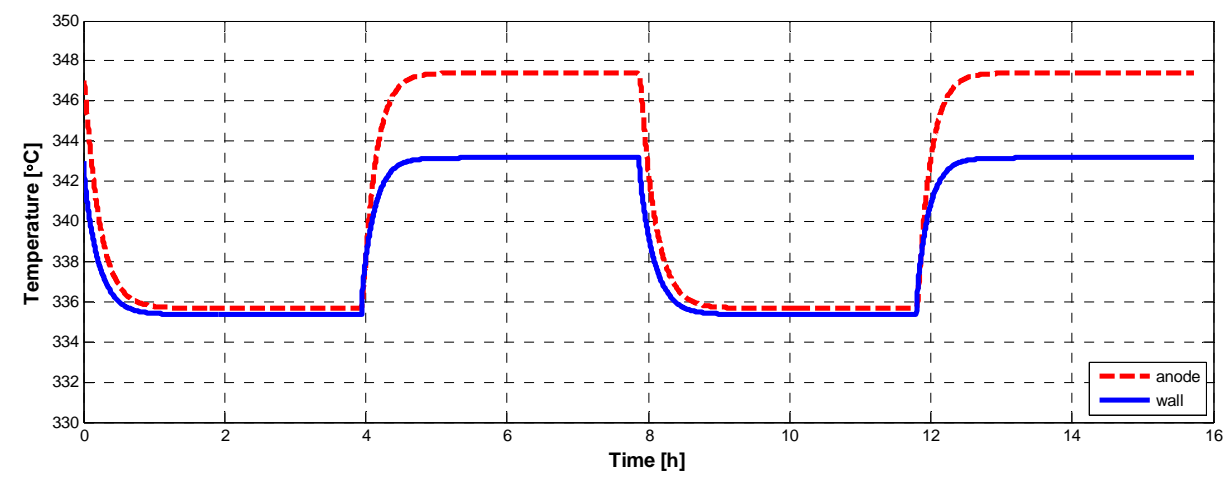

Figure 5.12 Temperature simulation running in cycles from lumped model 
Fig 5.11 and Fig 5.12 exhibit the simulated performance of the lumped model running in cycles, which verifies that the model is able to simulate the charge/discharge processes consistently.

In conclusion, the zero-dimensional lumped model developed in the present study was validated using published results and it was shown that the results from the lumped model have similar average behavior as the results of experiments and models from the literature. The model runs in seconds for each charge/discharge cycle, much faster than those from multi-dimensional model that takes up to hours to run. A few discrepancies are shown in the comparison in the details of curves. The reasons for the discrepancies could be different modeling strategies (zero-dimensional and multi-dimensional) used in different computational models, and can also result from some minor factors that are neglected when constructing the models; such differences should be kept to a minimum in order to establish confidence in the model predictions. More experiments are needed to assess the accuracy of the lumped computational model for $\mathrm{NaS}$ battery.

\subsection{Other Results and Analysis}

Apart from cell voltage, OCV and temperature, the lumped computational model for $\mathrm{NaS}$ battery can also predict processes associated with other parameters, such as cell resistance, activation potential, major losses, etc. In this section, cases of $\mathrm{NaS}$ battery running at $130 / 130 \mathrm{~mA} / \mathrm{cm}^{2}, 195 / 260 \mathrm{~mA} / \mathrm{cm}^{2}$ and $260 / 390 \mathrm{~mA} / \mathrm{cm}^{2}$ charge/discharge with cut-off voltages of $2.40 / 1.50 \mathrm{~V}, 2.60 / 1.20 \mathrm{~V}$ and $2.60 / 1.05 \mathrm{~V}$ respectively is adopted in order to analyze the activation potential, cell resistance and other behaviors. 


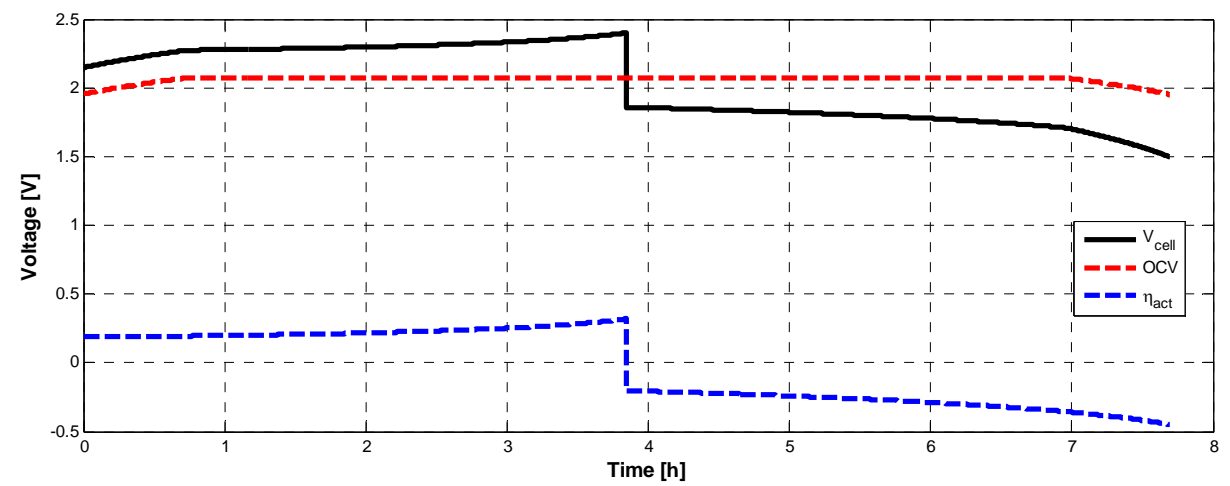

Figure 5.13 Electric characteristics of the NaS battery at $130 / 130 \mathrm{~mA} / \mathrm{cm}^{2}$

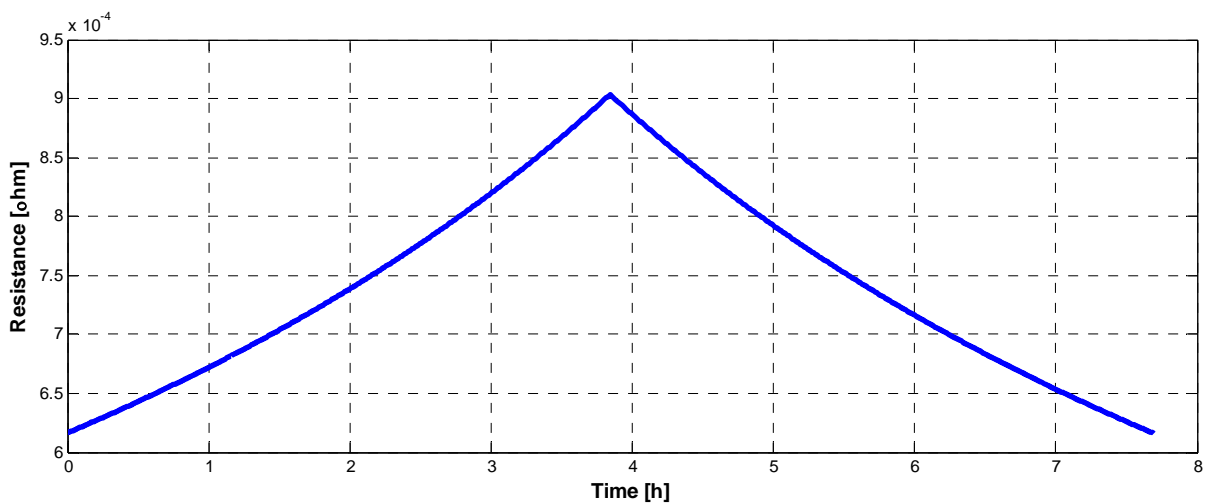

Figure 5.14 Cell resistance of the NaS battery at $130 / 130 \mathrm{~mA} / \mathrm{cm}^{2}$ 


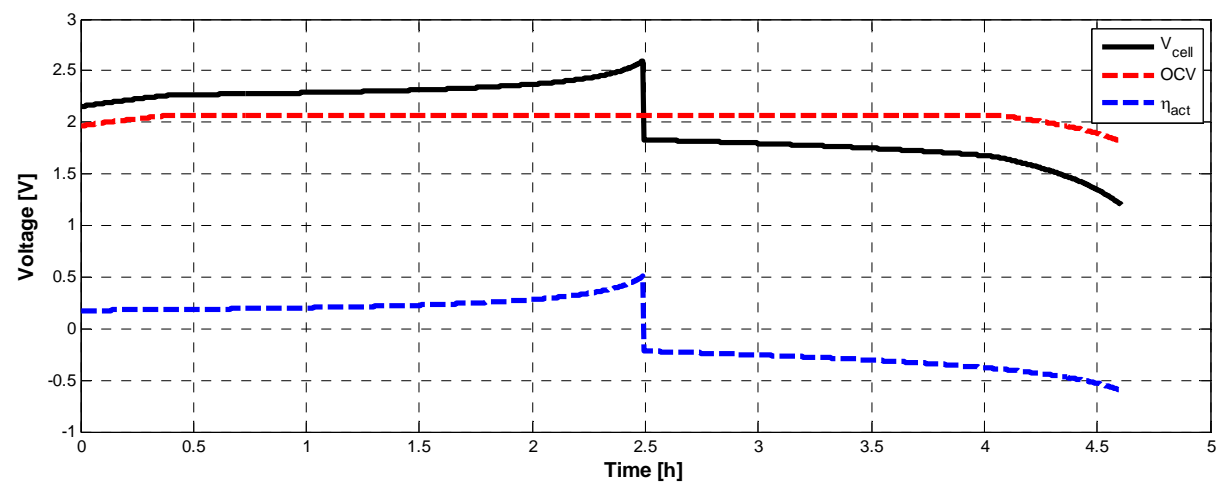

Figure 5.15 Electric characteristics of the NaS battery at 195/260 mA/cm ${ }^{2}$

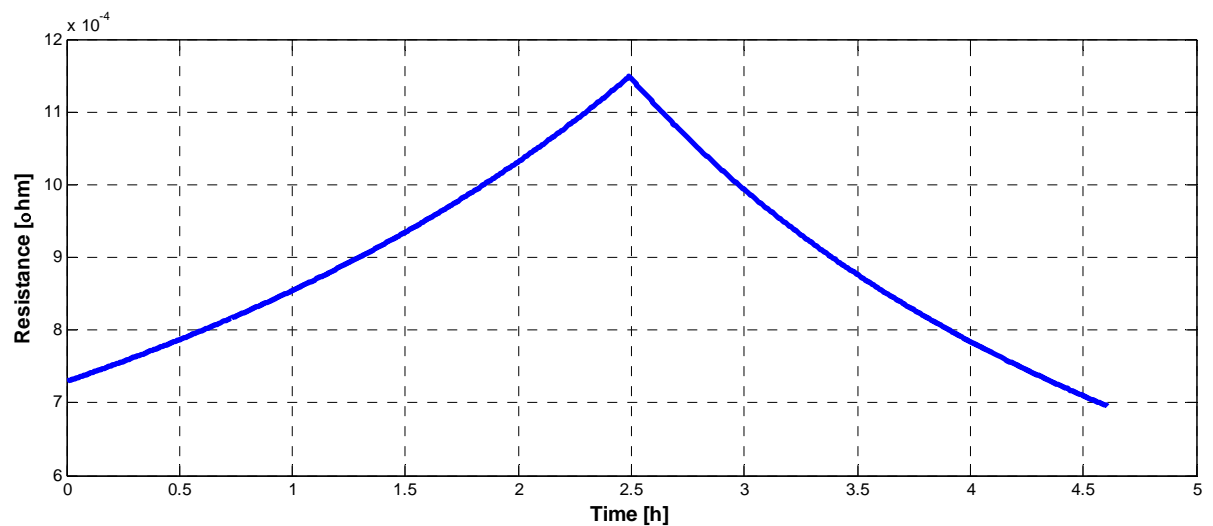

Figure 5.16 Cell resistance of the NaS battery at 195/260 mA/ $\mathrm{cm}^{2}$ 


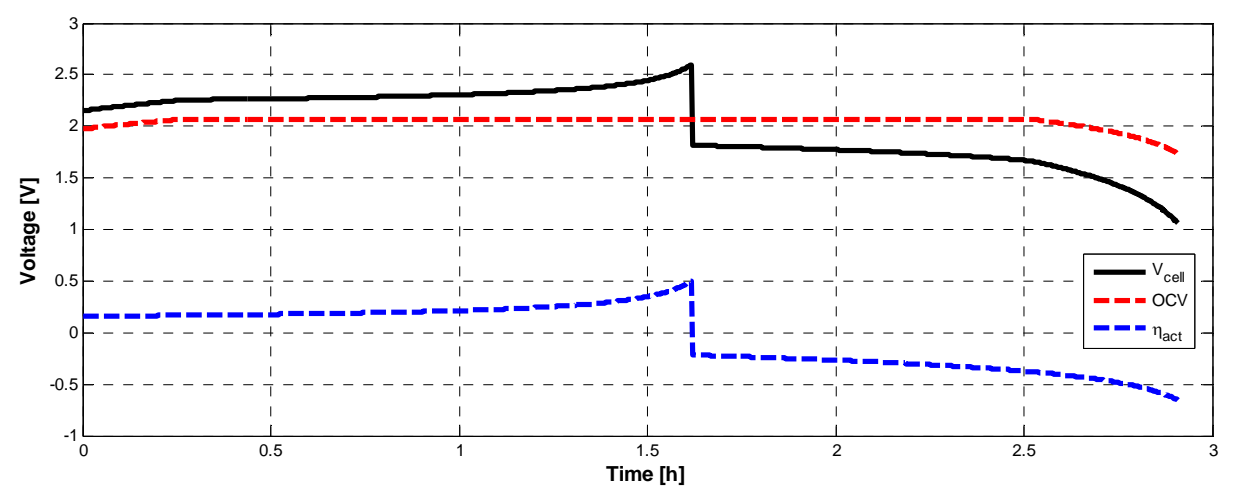

Figure 5.17 Electric characteristics of the NaS battery at $260 / 390 \mathrm{~mA} / \mathrm{cm}^{2}$

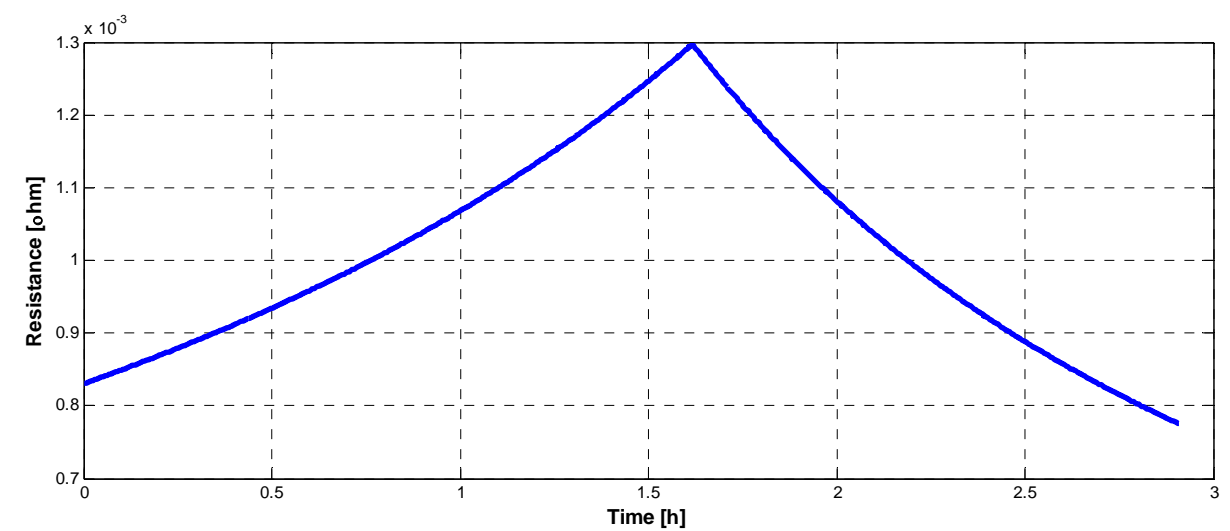

Figure 5.18 Cell resistance of the NaS battery at $260 / 390 \mathrm{~mA} / \mathrm{cm}^{2}$

Activation potential is shown in Fig 5.13, Fig 5.15 and Fig 5.17 in addition to $\mathrm{OCV}$ and cell voltage. It can be seen from the results that the cell voltage for a $\mathrm{NaS}$ battery is largely influenced by both the OCV and activation overpotential, while the loss from ohmic heat lends less influence compared to the former two. OCV is a dominant factor in a NaS battery modeling, since it is the difference of electrical potential between two terminals of a device when disconnected from any circuit, while the activation 
overpotential is also highly influential, because it is directly derived from the actual chemical reactions and the amount of all the reactants and products.

Cell resistance is calculated using the updated value from the amount of all the substances and their properties at each time step. The results are shown in Fig 5.14, Fig 5.16 and Fig 5.18. The results reveal that the resistance of a NaS battery is increasing in charging and decreasing in discharging stage. This trend is mainly due to the formation of sulfur and its huge resistance compared to the sodium polysulfide. The variation of cell resistance respect to time is not linear, and much larger resistance could appear if the battery is over charged. Thus it is better to control the extent of what state of charge the battery is supposed to utilize, in order to protect the NaS battery.

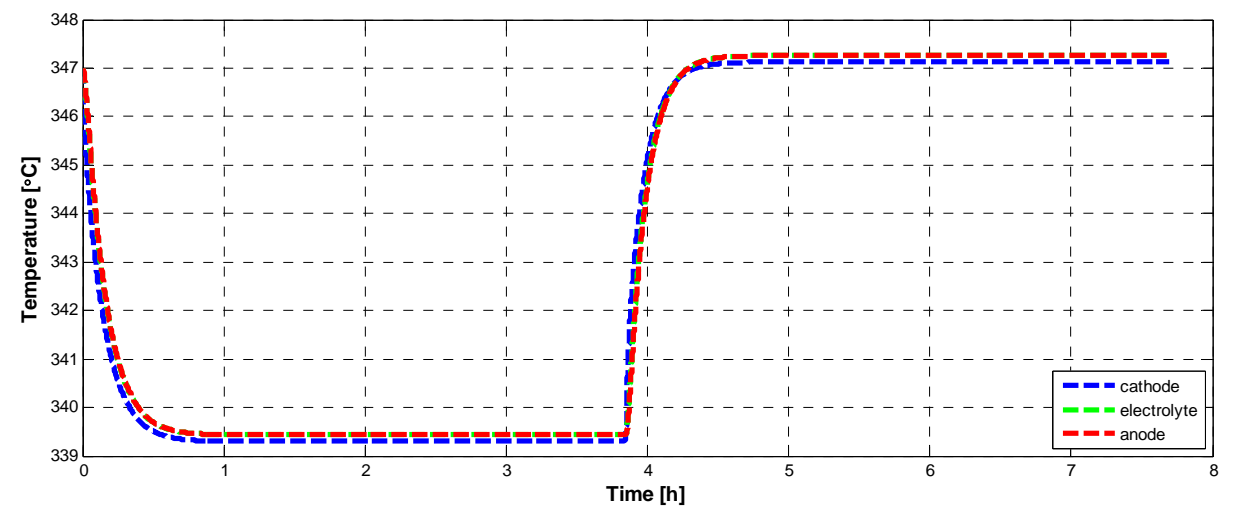

Figure 5.19 Thermal characteristics of the NaS battery at $130 / 130 \mathrm{~mA} / \mathrm{cm}^{2}$

Fig 5.19 shows the temperature profiles for cathode, electrolyte and anode respectively from the lumped model simulation. It is shown that the temperature rise during the discharging operation is higher than that during the charging, and the temperature rise attains a maximum value at the end of discharge, because the heat generation due to the entropy change is exothermic during the discharging operation and it reaches maximum at the end of the discharging. 
Since the temperature differences between the three components are very small, especially the difference between anode and electrolyte, enlarged views are displayed in the following figures.

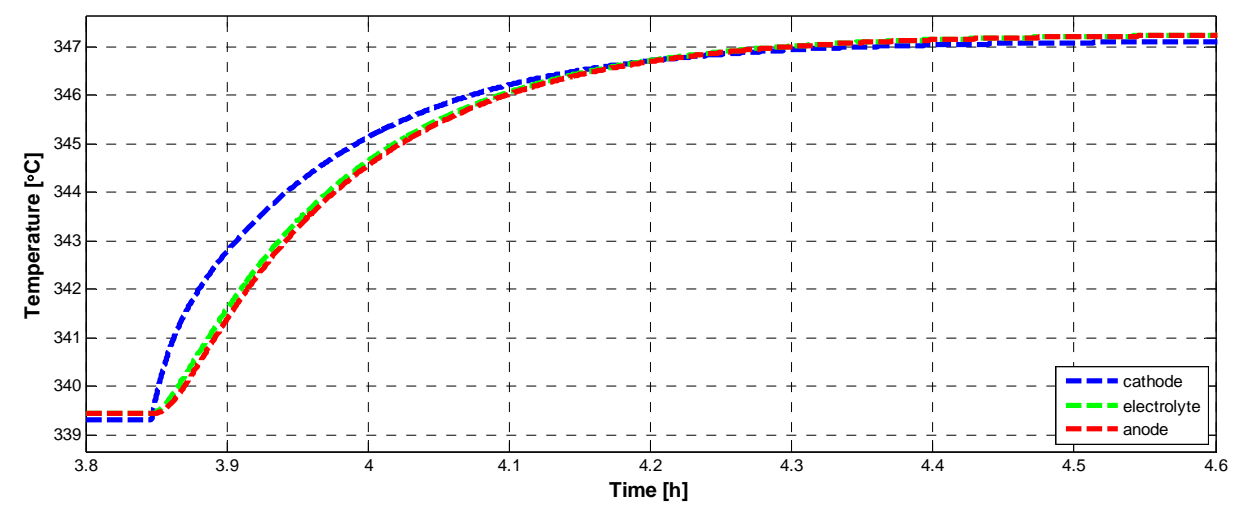

Figure 5.20 Temperature profiles at the beginning of discharging

Fig 5.20 reveals although the anode temperature is higher in equilibrium both for the charging and the discharging states, it is somewhat lower in the transient at the beginning of the discharging. This situation happens because when the battery begins discharging the reaction at the cathode is exothermic and its temperature rises faster, and the heat release also increases the temperature in the other components. However, the heat transferred to the anode is released so little to the environment, which makes the anode temperature higher and higher and eventually surpasses the cathode temperature, and an equilibrium state is reached. The transient in the condition of this case is about half an hour, and Fig 5.20 clearly shows the whole process. 


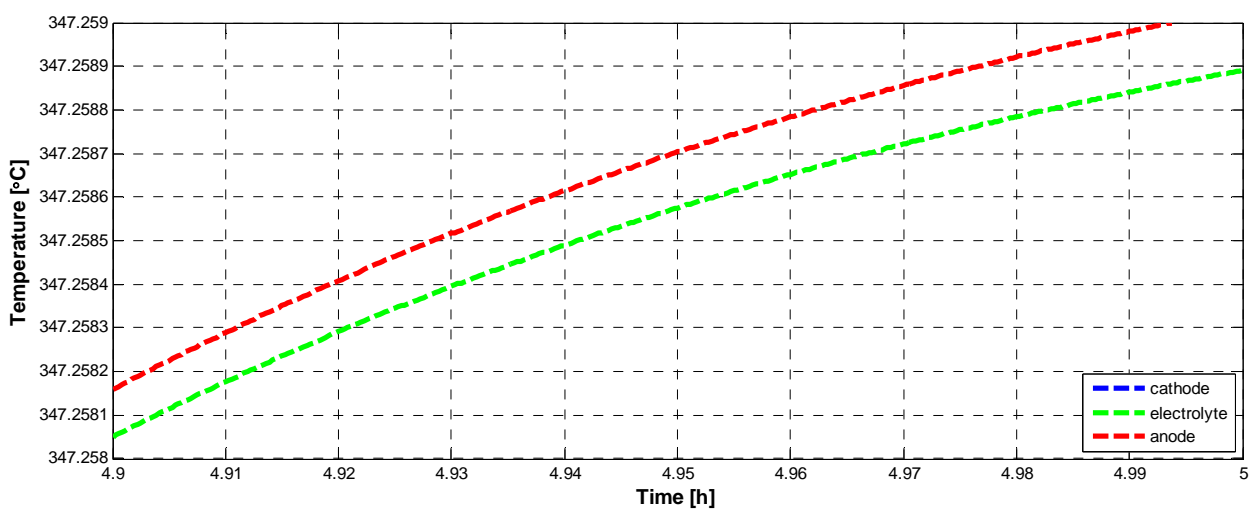

Figure 5.21 Temperature for anode and electrolyte (a)

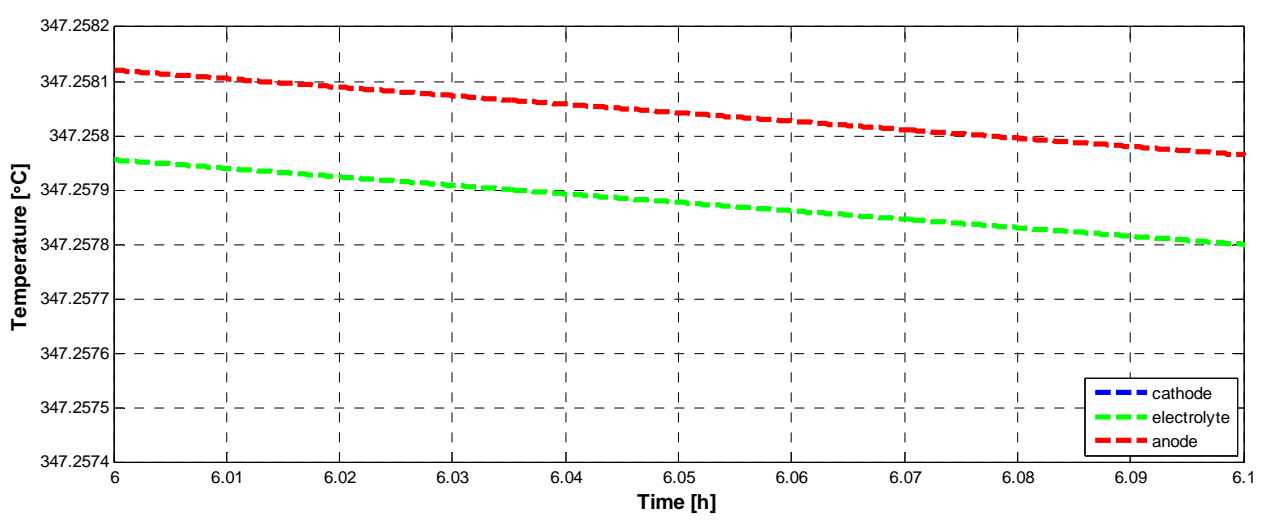

Figure 5.22 Temperature for anode and electrolyte (b)

The temperature profiles shown in Fig 5.21 and Fig 5.22 are enlarged views on the temperatures of anode and electrolyte in the equilibrium state of the discharging, at the time point of around 5 hours and 6 hours respectively. It can be seen that the temperatures of anode and electrolyte are almost identical, due to the similar properties of the two materials and the thickness of the electrolyte being as thin as about $1 \mathrm{~mm}$. 
It is also shown that although the battery reaches equilibrium after the transients diminish at the beginning of charging or discharging, the temperature does not really remain constant for all time. The temperature keeps increasing at a small scale in the first hour of discharging and decreasing after that.

Furthermore, comparisons are made for the numerical method when time step dt is set to be $0.1,1$ and 10s, respectively. The results are shown in Fig 5.23 to Fig 5.28.

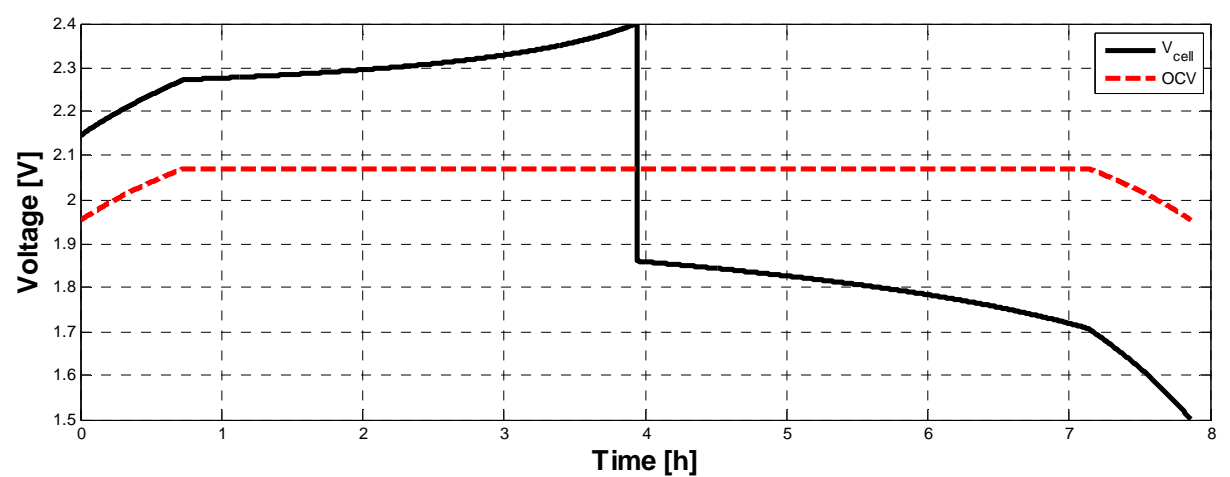

Figure 5.23 Voltage results at $\mathrm{dt}=0.1 \mathrm{~s}$

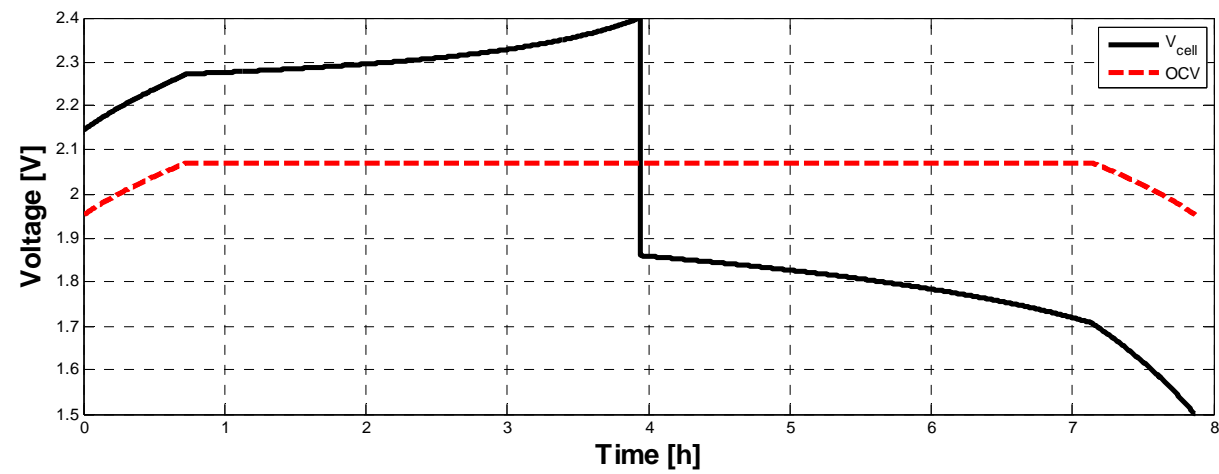

Figure 5.24 Voltage results at $\mathrm{dt}=1 \mathrm{~s}$ 


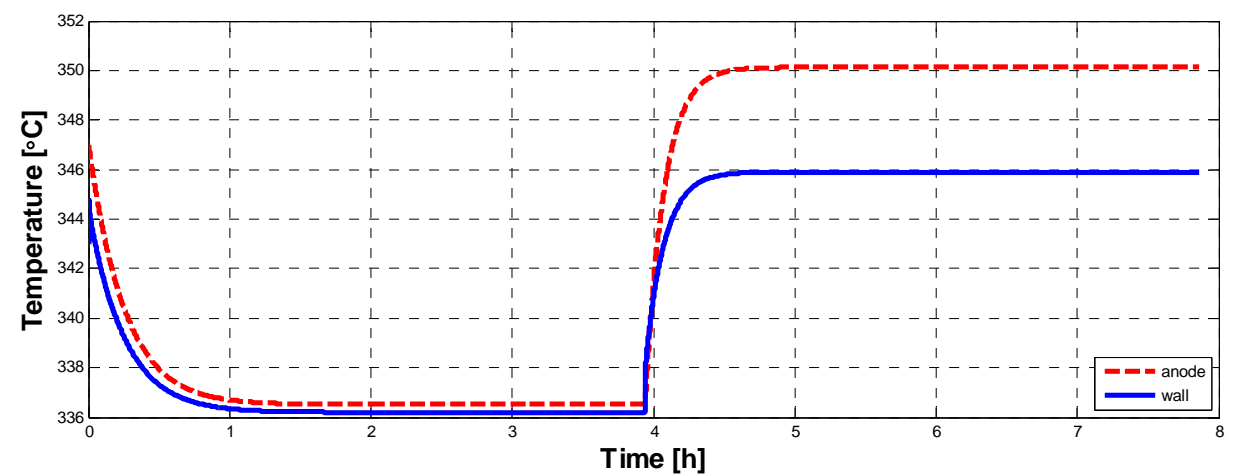

Figure 5.25 Temperature results at $\mathrm{dt}=0.1 \mathrm{~s}$

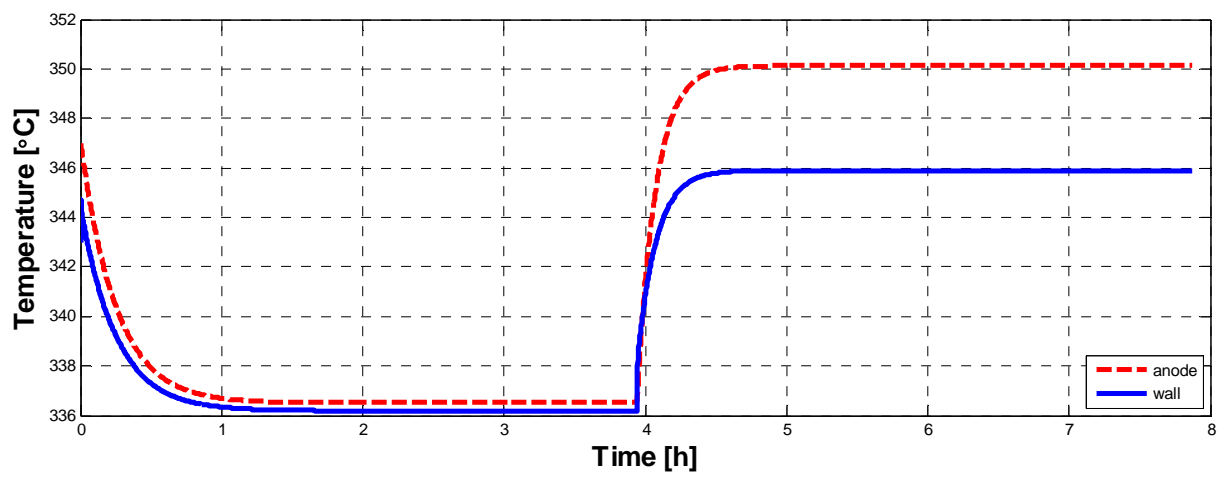

Figure 5.26 Temperature results at $\mathrm{dt}=1 \mathrm{~s}$

It can be seen when time step is set to be $1 \mathrm{~s}$ or smaller, the figures show nearly identical results. However when time step is larger than $1 \mathrm{~s}$, the temperature profile cannot be obtained due to its stiffness from different source terms. Therefore, the time step level of $1 \mathrm{~s}$ is the most preferable choice for the Euler method used in the current computational 
model. This seems a little surprising for the explicit Euler method used, and it must be further investigated.

Some parameter changes may influence the outcome of the results. For example, when ambient temperature is changed from $335^{\circ} \mathrm{C}$ to $250^{\circ} \mathrm{C}$, the temperature drops and the results are indicated in Fig 5.27

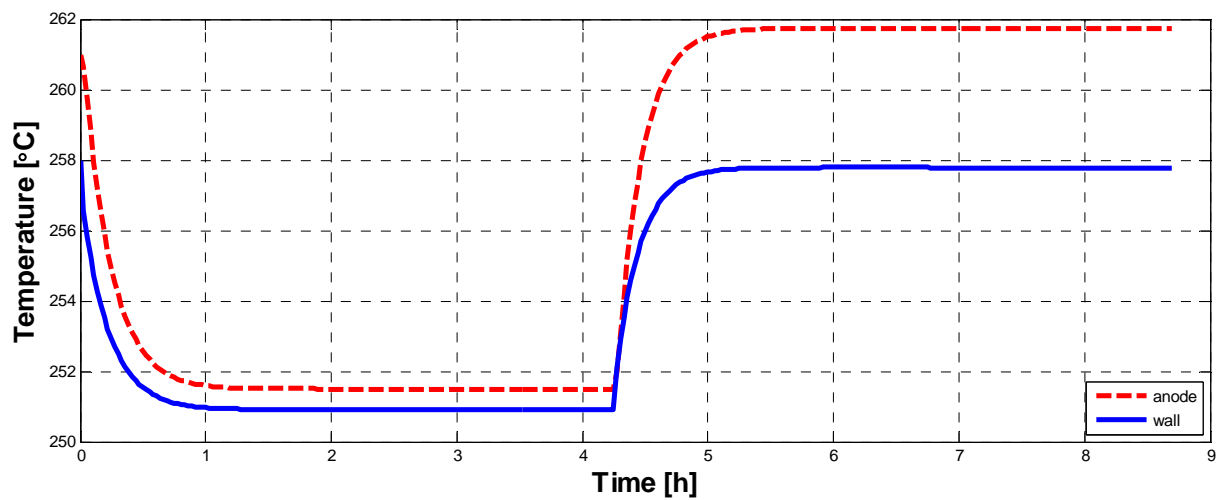

Figure 5.27 Temperature results when ambient temperature is $250^{\circ} \mathrm{C}$

Another example is given when the current density added to the battery is periodic current density instead of constant. The results are shown in Fig 5.28 to Fig 5.30.

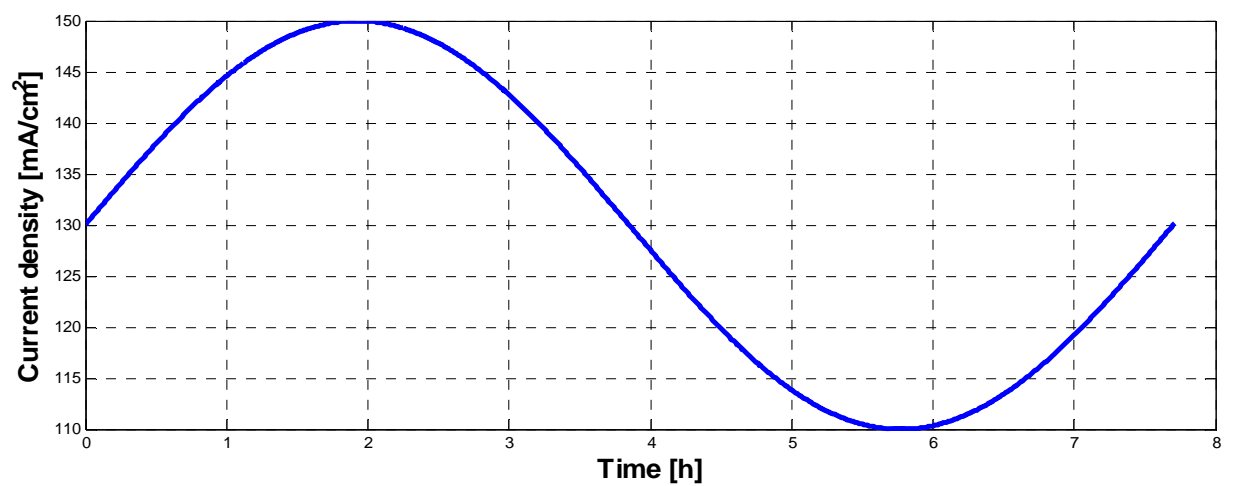

Figure 5.28 Periodic current density from input 


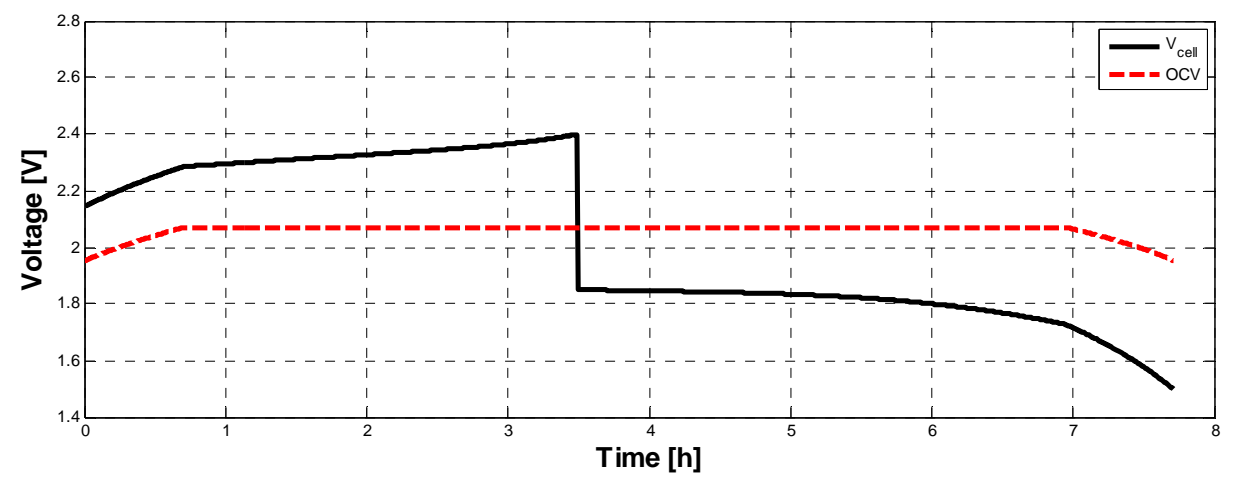

Figure 5.29 Voltage results under given periodic current density

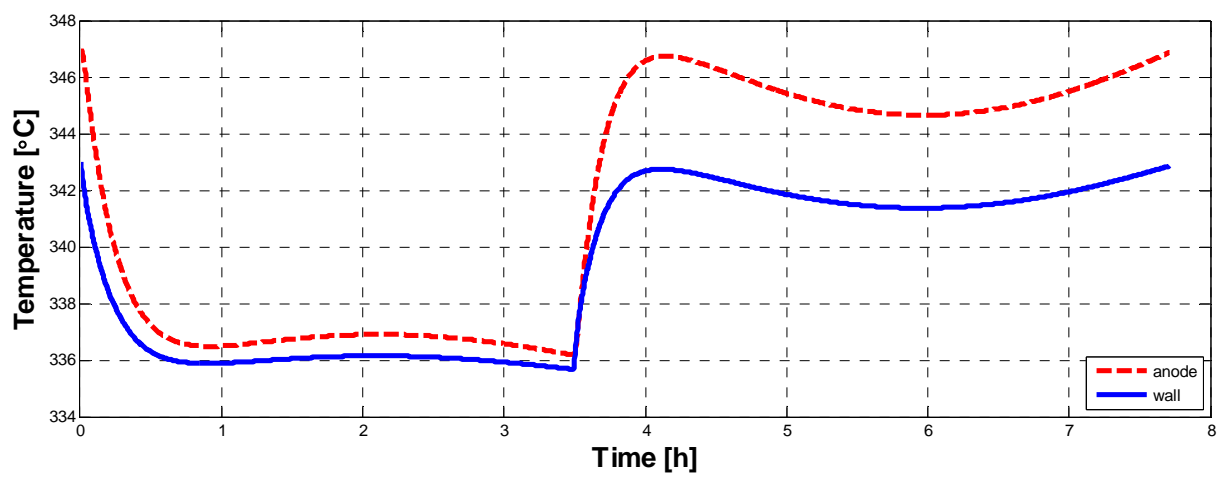

Figure 5.30 Temperature results under given periodic current density

In the control process of batteries, Depth of Discharge (DOD) or its counterpart, State of Charge (SOC), is often used. DOD is used to describe how deeply the battery is discharged; it is the fraction of the elemental sulfur which has been converted to polysulfides [10], i.e. $\frac{S_{\text {converted }}}{S_{\text {initial }}}$. An example of DOD involved simulation using the lumped model is shown in Fig 5.31. 


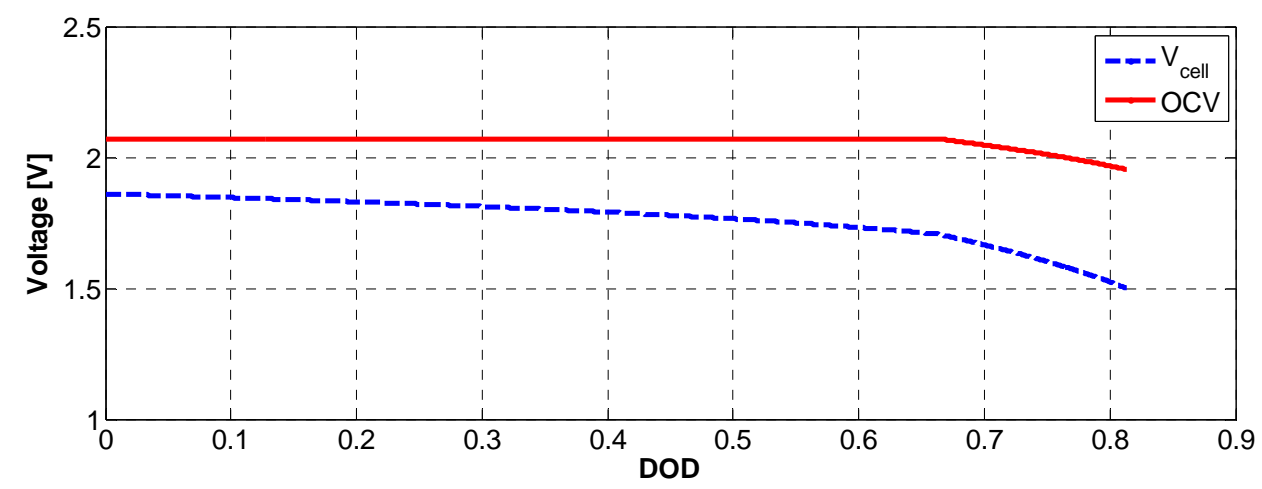

Figure 5.33 (a) Voltage results for discharging

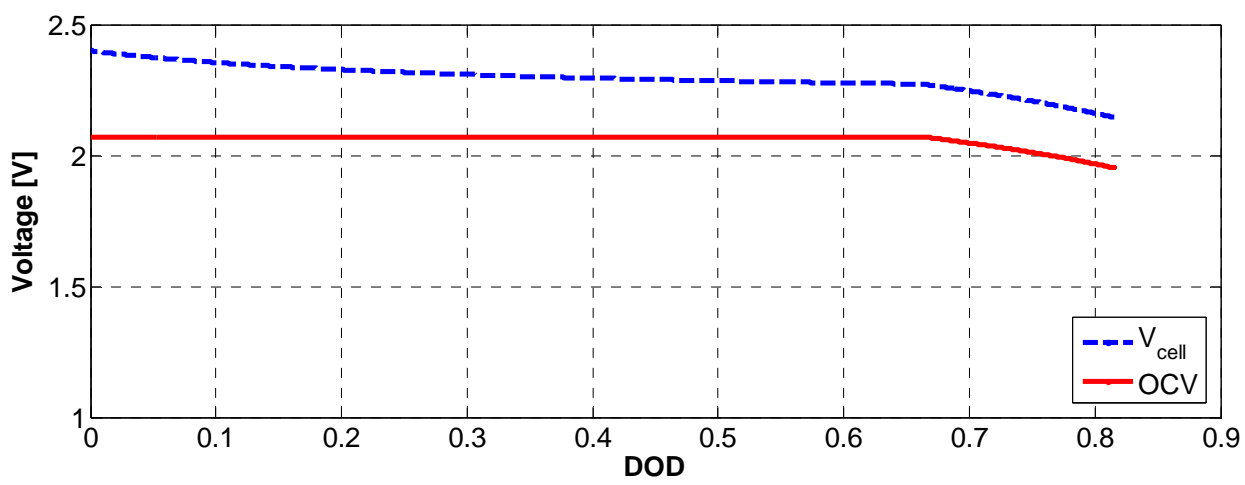

Figure 5.33 (b) Voltage results for charging

To sum up, the performance curves simulated from the lumped computational model for NaS battery can be applied to decrease the time and expense required to complete the design procedure of $\mathrm{NaS}$ battery. They can be utilized in different $\mathrm{NaS}$ battery cases to analyze and lend credence to the control of battery performances. The model developed can also be used as part of control algorithms for $\mathrm{NaS}$ and similar battery systems. 


\section{Chapter 6}

\section{Conclusions and Future Work}

\subsection{Conclusions}

A zero-dimensional lumped computational model for $\mathrm{NaS}$ battery is developed. A control volume for each of the anode, solid electrolyte and cathode is used to develop the computational model. This approach is suitable for fast performance simulation of a $\mathrm{NaS}$ battery at a fractional cost of multi-dimensional models.

Integral equations for a $\mathrm{NaS}$ battery are deduced from basic conservation of species, mass, charge and energy, respectively. Equations concerning electrochemical relationships are also deduced, which are central to the battery model. These equations form the foundation of developing the lumped model for NaS battery.

Iterative procedures are applied to implement the integral equations to a computational solution. Euler method is used explicitly for the time marching, and all the properties are updated in each time level.

The lumped model developed in the present study was validated using published results and it was shown that the results from the lumped model have almost identical average behavior as the results of experiments and models from the literature.

It can be seen from results that the cell voltage for a NaS battery is largely influenced by both the OCV and activation overpotential, while the loss from ohmic heat has less influence compared to the former two. The variation of cell resistance respect to time is not linear, and much larger resistance could appear if the battery is over charged. 
Thus it is better to control the extent of what state of charge the battery is supposed to utilize, in order to protect the NaS battery.

The results also show the endothermic and exothermic effects on temperature during the charging and discharging states, respectively. When equilibrium state is reached, the temperatures of anode and electrolyte are almost identical, while the cathode temperature is comparatively lower and the difference is more obvious in the discharging state.

A few discrepancies are observed in the comparison of the details of battery processes. The reasons for the discrepancies could be due to different modeling strategies (zero-dimensional and multi-dimensional) used in different computational models, or they may also result from some minor factors that are neglected when constructing model. Some of the factors that may affect the result are the concentration polarization, due to the zero-dimensionality of the lumped model, or the ionization process between sodium and sodium ion that are neglected for simplicity.

Application to a typical tubular NaS battery under several operation conditions demonstrated that the proposed model can be used to aid in the design procedure of $\mathrm{NaS}$ battery. They can also be utilized in different $\mathrm{NaS}$ battery cases to analyze and lend credence to the control of battery performances.

\subsection{Potential Future Work}

1. Some factors, such as the double layer capacitance, concentration losses, ionization process in the anode, other sources of heat transfer between the control volume and 
environment, etc., are neglected in the current model, which require further study to give a better simulation of $\mathrm{NaS}$ battery.

2. The thermodynamic model should involve more details in order to reduce the differences compared with results in the literature.

3. More experiments are needed to assess the accuracy of the lumped computational model developed in this study.

4. The lumped model could also be adapted to analyze the effect of multi-cells of NaS battery either in series or parallel.

5. Comparisons and performance analysis can be performed together with other models such as the three-dimensional NaS battery model and network model. 


\section{References}

[1] H. Kawamoto and Y. Kusakabe, "Performance and Thermal Behavior of Sodium-Sulfur Cell under High Current Density Operations," Journal of The Electrochemical Society, vol. 136, no. 5, pp. 1355-1361, 1989.

[2] D. Docimd, M. Ghannatpishe, M. Rothenbercer, C. Rahn and H. Fathy, "the Lithium-ion Battery Modeling Challenge: a Dynamic Systems and Control Perspective," ASME Dynamic Systems and Control, vol. 2, no. 2, pp. 7-14, 2014.

[3] Z. Wen, "Study on Energy Storage Technology of Sodium Sulfur Battery and it's Application in Power System," in International Conderence on Power System Technology, Chongqing, 2006.

[4] Carl Johan Rydh, Bjorn A. Sanden, "Energy analysis of batteries in photovoltaic systems. Part I," Energy Conversion and Management, vol. 46, no. 11-12, pp. 19571979, 2005.

[5] Carl Johan Rydh, Bjorn A. Sanden, "Energy analysis of batteries in photovoltaic systems. Part II," Energy Conversion and Management, vol. 46, no. 11-12, pp. 19802000, 2005.

[6] A. E. Sarasua, M. G. Molina, D. E. Pontoriero and P. E. Mercado, "Modelling of NAS energy storage system for power system applications," in Transmission and Distribution Conference and Exposition: Latin America (T\&D-LA), 2010 IEEE/PES, Sao Paulo, 2010.

[7] Etsuji Kodama and Yoshihiko Kurashima, "Development of a compact sodium-sulphur battery," Power Engineering Journal, vol. 13, no. 3, pp. 136-141, 1999.

[8] Taku Oshima, Masaharu Kajita and Akiyasu Okuno, "Development of Sodium-Sulfur Batteries," International Journal of Applied Ceramic Technology, vol. 1, no. 3, pp. 269276, 2004.

[9] T. Hatta, "Recent Applications of NAS Battery System in the United States and in Japan," in Electrical Energy Storage Applications and Technologies, Nagoya, 2011.

[10] J. L. Sudworth and A. R. Tilley, The Sodium Sulfur Battery, London: Chapman and Hall Ltd, 1985. 
[11] B. e. al., "Sodium-Sulfur Battery and Process For Its Production". Germany Patent 4,038,464, 26 July 1977.

[12] S. e. al., "Planar Sodium-Sulfur Electrical Storage Cell". USA Patent 5,053,294, 1 Oct. 1991.

[13] Lakshmi Vijayan and G. Govindaraj, "NASICON Materials: Structure and Electrical Properties," in Polycrystalline materials - theoretical and practical aspects, In Tech, 2011, p. 176.

[14] A. Herczog, "Sodium Ion Conducting Glasses for the Sodium-Sulfur Battery," Journal of The Electrochemical Society, vol. 132, no. 7, pp. 1539-1545, 1985.

[15] Xiaochuan Lu, Guanguang Xia, John P. Lemmon, Zhenguo Yang, "Advanced materials for sodium-beta alumina batteries: Status, challenges and perspectives," Journal of Power Sources, vol. 195, no. 9, pp. 2431-2442, 2010.

[16] e. a. Gotou, "Power Storage System using Sodium-Sulfur Batteries". Japan Patent 4,578,325, 25 Mar. 1986.

[17] D. Mazza, "Modeling Ionic Conductivity in Nasicon Structures," Journal of Solid State Chemistry, vol. 156, no. 1, pp. 154-160, 2001.

[18] H.-P. Hong, "Crystal structures and crystal chemistry in the system Na1+xZr2SixP3-xO12," Materials Research Bulletin, vol. 11, no. 2, p. 173-182, 1976.

[19] Catherine Housecroft and Alan G. Sharpe, Inorganic Chemistry 3rd Edition, London: Prentice Hall, 2008.

[20] Monica Pozzo, Michael P. Desjarlais, Dario Alfè, "Electrical and thermal conductivity of liquid sodium from first-principles calculations," Physical Review B, vol. 84, no. 5, p. 054203, 2011.

[21] B. Cleaver, "Properties of fused polysulphides I," Electrochimica acta, vol. 18, no. 10, pp. 719-739, 1973.

[22] B. Cleaver, "Properties of dused polysulphides VI," Electrochimica Acta, vol. 36, no. 34, pp. 667-671, 1991.

[23] B. Cleaver, A. J. Davies, "Properties of fused polysulphides - II," Electrochemica Acta, vol. 18 , no. 10, pp. 727-731, 1973.

[24] B. Cleaver, A. J. Davies, "Properties of fuesd polysulphides III," Electrochimica Acta, 
vol. 18 , no. 10 , pp. $733-739,1973$.

[25] D.-G. Oei, "The Sodium-Sulfur System. I. Differential Thermal Analysis," Inorganic Chemistry, vol. 12, no. 2, pp. 435-437, 1973.

[26] J. G. Gibson, "The distribution of potential and electrochemical reaction rate in molten polysulfide electrodes," J. Appl. Electrochem., vol. 4, pp. 125-134, October 1973.

[27] B. D. M.W. Breiter, "Potential distribution model for rechargeable sulphur electrodes in sodium-sulfur cells," Journal of Applied Electrochemistry, vol. 9, pp. 291-299, March 1979.

[28] M. Wada, "Numerical Simulation of the Dual Mat Sulfur Electrode of a Sodium Sulfur Cell," Journal of The Electrochemical Society, vol. 134, no. 3, pp. 631-638, 1987.

[29] Y.-K. Kao and P. C. Wayner, "The Transient Response of the Sulfur/Polysulfide Electrode Based on a Varying Concentration Model," Journal of The Electrochemical Society, vol. 124, no. 2, pp. 230-236, 1977.

[30] H. Kawamoto and M. Wada, "Two-Dimensional Distribution of Electrochemical Reaction Rate in Porous Sulfur Electrodes of Sodium-Sulfur Cells," Journal of The Electrochemical Society, vol. 134, no. 2, pp. 280-285, 1987.

[31] H. Kawamoto, "Two-Dimensional Distribution of Sodium Polysulfide Composition in Sulfur Electrodes of Sodium-Sulfur Cells," Journal of The Electrochemical Society, vol. 136, no. 7, pp. 1851-1860, 1989.

[32] W. B. Gu, C. Y. Wang and B. Y. Liaw, "Numerical Modeling of Coupled Electrochemical and Transport Processes in Lead-Acid Batteries," J. Electrochemical Soc., vol. 144, no. 6, pp. 2053-2061, 1997.

[33] J. Divisek, F. Bodewig, J. Mergel, H. Lippert and B. Kastening, "Mass Transport Phenomena in the Molten Sulfur-Sodium Polysulfide System," Journal of The Electrochemical Society, vol. 127, no. 2, pp. 357-363, 1980.

[34] IEEE, "Adoption of the Project Management Institute Standard A Guide to the Project Management Body of Knowledge," in IEEE Guide Fourth Edition, 2012, p. 452.

[35] S. R. Pakalapati, Ph.D. Dissertation: A New Reduced Order Model For Solid Oxide Fuel Cells, Morgantown: West Virginia University, 2006.

[36] A. L. F. I. a. D. D. T. Bergman, Fundamentals of Heat and Mass Transfer Seventh Edition, NJ: John Wiley \& Sons, Inc., 2011. 
[37] B. Cleaver, "Properties of fused polysulphides - I. The electrical conductivity of fused sodium and potassium polysulfides," Electrochemica Acta, vol. 18, pp. 719-726, 1973.

[38] N. Gupta and R. Tischer, "Thermodynamic and Physical Properties of Molten Sodium Polysulfides from Open-Circuit Voltage Measurements," Journal of The Electrochemical Society, vol. 119, no. 8, pp. 1033-1037, 1972.

[39] G. Janz, C. Allen, N. Bansal, R. Murphy and R. Tomkins, "Physical Properties Data Compilations Relevan to Energy Storage II," National Standard Reference Data Series (NSRDS), 1978.

[40] G. Janz, C. Allen, N. Bansal, R. Murphy and R. Tomkins, "G. Miller and D. Paquette," National Standard Reference Data Series (NSRDS), 1979.

[41] G. Janz and R. Tomkins, "Physical Properties Data Compilations Relevan to Energy Storage IV," National Standard Reference Data Series (NSRDS), 1981.

[42] D. Ginnings, T. Douglas and A. Ball, "Heat Capacity of Sodium Between $0^{\circ}$ and $900^{\circ} \mathrm{C}$, the Triple Point and Heat of Fusion," National Bureau of Standards, 1950. 


\section{Appendix I \\ Modeling of losses from mass transport/concentration}

In order to study the losses from mass transport/concentration, a limiting voltage

$V_{l}$ is assumed at which the electrode material is used up at a rate equal to its maximum supply speed. The concentration loss, $\eta_{c}$, is calculated by

$$
\eta_{c}=\frac{R T}{2 F} \ln \left(1-\frac{V}{V_{l}}\right)
$$

where $V$ is the cell voltage. The limiting voltage can be obtained from the results showed in Chapter 5. Take the case with the current density of $130 / 130 \mathrm{~mA} / \mathrm{cm}^{2}$ for instance. The limiting voltage is the cut-off voltage, which is $2.4 \mathrm{~V}$ for the charging and $1.5 \mathrm{~V}$ for the discharging.

Further study is needed in order to adopt this model into the lumped $\mathrm{NaS}$ computational model in the present work. 


\section{Appendix II}

The properties used in the NaS battery model are as indicated in Table a

Table a Properties used in the NaS battery at 300 to $400^{\circ} \mathrm{C}$

\begin{tabular}{|l|l|}
\hline Parameter & Value \\
\hline Density of sulfur $\left(\mathrm{g} / \mathrm{cm}^{3}\right)$ & 1.819 \\
\hline Density of $\mathrm{Na}_{2} S_{3}\left(\mathrm{~g} / \mathrm{cm}^{3}\right)$ & 1.880 \\
\hline Density of sodium $\left(\mathrm{g} / \mathrm{cm}^{3}\right)$ & 0.927 \\
\hline Density of graphite mat $\left(\mathrm{g} / \mathrm{cm}^{3}\right)$ & 2.230 \\
\hline Molar mass of sulfur $(\mathrm{g} / \mathrm{mol})$ & 32.06 \\
\hline Molar mass of $\mathrm{Na}_{2} S_{3}(\mathrm{~g} / \mathrm{mol})$ & 174.22 \\
\hline Molar mass of sodium $(\mathrm{g} / \mathrm{mol})$ & 22.99 \\
\hline Electric conductivity of sulfur $(/ \Omega / \mathrm{m})$ & $5.0 \mathrm{e}-16$ \\
\hline Electric conductivity of $\mathrm{Na}{ }_{2} S_{3}(/ \Omega / \mathrm{m})$ & $3.5 \mathrm{e}-5$ \\
\hline Electric conductivity of sodium $(/ \Omega / \mathrm{m})$ & $8.0 \mathrm{e} 6$ \\
\hline Electric conductivity of graphite mat $(/ \Omega / \mathrm{m})$ & $8.3 \mathrm{e} 4$ \\
\hline Specific heat capacity of sulfur $(\mathrm{J} / \mathrm{g} / \mathrm{K})$ & 0.71 \\
\hline Specific heat capacity of $\mathrm{Na}{ }_{2} S_{3}(\mathrm{~J} / \mathrm{g} / \mathrm{K})$ & 0.52 \\
\hline Specific heat capacity of sodium $(\mathrm{J} / \mathrm{g} / \mathrm{K})$ & 1.29 \\
\hline Specific heat capacity of graphite mat $(\mathrm{J} / \mathrm{g} / \mathrm{K})$ & 0.846 \\
\hline Specific heat capacity of beta-alumina $(\mathrm{J} / \mathrm{g} / \mathrm{K})$ & 0.90 \\
\hline Specific heat capacity of outer wall $(\mathrm{W} / \mathrm{m} / \mathrm{K})$ & 0.62 \\
\hline Heat conductivity of sulfur $(\mathrm{W} / \mathrm{m} / \mathrm{K})$ & 0.205 \\
\hline Heat conductivity of $\mathrm{Na}{ }_{2} S_{3}(\mathrm{~W} / \mathrm{m} / \mathrm{K})$ & 0.27 \\
\hline Heat conductivity of graphite mat $(\mathrm{W} / \mathrm{m} / \mathrm{K})$ & 300 \\
\hline
\end{tabular}


Table a (continued) Properties used in the NaS battery at 300 to $400^{\circ} \mathrm{C}$

\begin{tabular}{|l|l|}
\hline Parameter & Value \\
\hline Heat conductivity of sodium $(\mathrm{W} / \mathrm{m} / \mathrm{K})$ & 200 \\
\hline Heat conductivity of outer wall $(\mathrm{W} / \mathrm{m} / \mathrm{K})$ & 44.4 \\
\hline Entropy of sulfur $(\mathrm{J} / \mathrm{mol} / \mathrm{K})$ & 36.85 \\
\hline Entropy of $\mathrm{Na}_{2} S_{3}(\mathrm{~J} / \mathrm{mol} / \mathrm{K})$ & -41.84 \\
\hline Entropy of sodium $(\mathrm{J} / \mathrm{mol} / \mathrm{K})$ & 60.5 \\
\hline Entropy of electron $(\mathrm{J} / \mathrm{mol} / \mathrm{K})$ & 31.715 \\
\hline Tortuosity factor $\beta$ & 1.5 \\
\hline Porosity $\varepsilon$ & 0.79 \\
\hline Ionic resistivity of bate-alumina $(\Omega \cdot \mathrm{cm})$ & 5 \\
\hline Effective resistivity of the graphite mat $(\Omega \cdot \mathrm{cm})$ & 2 \\
\hline
\end{tabular}

